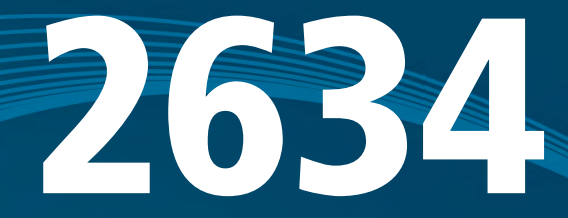

\title{
INDUTORES DO GASTO DIRETO DO MINISTÉRIO DA SAÚDE EM MEDICAMENTOS (2010-2019)
}

Fabiola Sulpino Vieira

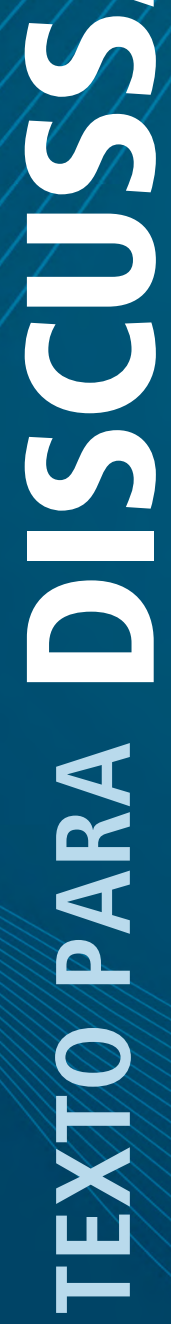





\section{TEXTO PARA DISCUSSÃO}

Brasília, março de 2021

INDUTORES DO GASTO DIRETO DO MIINISTÉRIO DA SAÚDE EIM

MEDICAMENTOS (2010-2019)1

Fabiola Sulpino Vieira ${ }^{2}$

1. Agradeço a José Roberto Peters, matemático e consultor técnico na área da saúde, pela extração e disponibilização dos dados sobre compras do Ministério da Saúde (MS) constantes do Sistema Integrado de Administração de Serviços Gerais (Siasg).

2. Especialista em políticas públicas e gestão governamental na Diretoria de Estudos e Políticas Sociais (Disoc) do Ipea. E-mail:<fabiola.vieira@ipea.gov.br>. 


\section{Governo Federal \\ Ministério da Economia \\ Ministro Paulo Guedes}

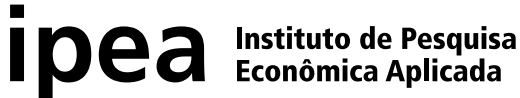

Fundação pública vinculada ao Ministério da Economia, o Ipea fornece suporte técnico e institucional às ações governamentais - possibilitando a formulação de inúmeras políticas públicas e programas de desenvolvimento brasileiros - e disponibiliza, para a sociedade, pesquisas e estudos realizados por seus técnicos.

\section{Presidente}

Carlos von Doellinger

Diretor de Desenvolvimento Institucional Manoel Rodrigues Junior

Diretora de Estudos e Políticas do Estado, das Instituições e da Democracia

Flávia de Holanda Schmidt

\section{Diretor de Estudos e Políticas \\ Macroeconômicas \\ José Ronaldo de Castro Souza Júnior}

Diretor de Estudos e Políticas Regionais, Urbanas e Ambientais

Nilo Luiz Saccaro Júnior

Diretor de Estudos e Políticas Setoriais de Inovação e Infraestrutura

André Tortato Rauen

\section{Diretora de Estudos e Políticas Sociais}

Lenita Maria Turchi

Diretor de Estudos e Relações Econômicas

e Políticas Internacionais

Ivan Tiago Machado Oliveira

\footnotetext{
Assessor-chefe de Imprensa

e Comunicação (substituto)

João Cláudio Garcia Rodrigues Lima

Ouvidoria: http://www.ipea.gov.br/ouvidoria

URL: http://www.ipea.gov.br
}

\section{Texto para Discussão}

Publicação seriada que divulga resultados de estudos e pesquisas em desenvolvimento pelo Ipea com o objetivo de fomentar o debate e oferecer subsídios à formulação e avaliação de políticas públicas.

(C) Instituto de Pesquisa Econômica Aplicada - ipea 2021

Texto para discussão / Instituto de Pesquisa Econômica Aplicada.- Brasília : Rio de Janeiro : Ipea , 1990-

ISSN 1415-4765

1.Brasil. 2.Aspectos Econômicos. 3.Aspectos Sociais. I. Instituto de Pesquisa Econômica Aplicada.

CDD 330.908

As publicações do Ipea estão disponíveis para download gratuito nos formatos PDF (todas) e EPUB (livros e periódicos).

Acesse: http://www.ipea.gov.br/portal/publicacoes

As opiniões emitidas nesta publicação são de exclusiva e inteira responsabilidade dos autores, não exprimindo, necessariamente, o ponto de vista do Instituto de Pesquisa Econômica Aplicada ou do Ministério da Economia.

É permitida a reprodução deste texto e dos dados nele contidos, desde que citada a fonte. Reproduções para fins comerciais são proibidas. 


\section{SUMÁRIO}

SINOPSE

ABSTRACT

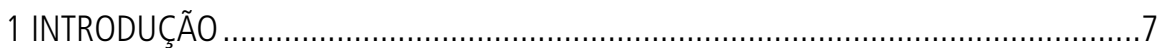

2 DETERMINANTES E INDUTORES DO GASTO EM MEDICAMENTOS..........................10

3 MÉTODOS

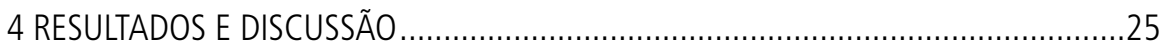

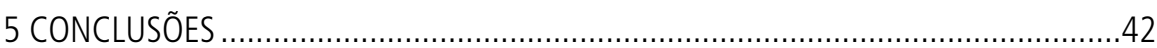

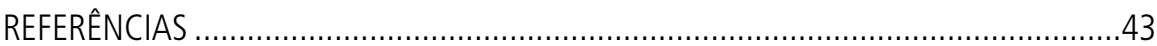





\section{SINOPSE}

O objetivo deste texto é analisar a contribuição dos principais indutores do gasto direto do Ministério da Saúde (MS) em medicamentos que integram a lista dos componentes da assistência farmacêutica (AF) no período de 2010 a 2019. Foram utilizados dados de aquisiçóes constantes do Sistema Integrado de Administração de Serviços Gerais (Siasg). Os medicamentos foram categorizados segundo o sistema de classificação ATC/DDD (Anatomical Therapeutic Chemical Classification System/defined daily doses) da Organização Mundial da Saúde (OMS). As unidades físicas de compra dos produtos foram transformadas em número de doses diárias definidas (DDD) para cada fármaco e o preço unitário foi convertido para preço por DDD. Com o suporte do software RStudio versão 1.3.1056 e do pacote estatístico IndexNumR, mensurou-se a contribuição dos principais indutores do gasto em medicamentos: preço, quantidade e resíduo (escolhas terapêuticas). Os resultados mostram grande variação do gasto do MS em medicamentos da lista dos componentes da AF no período de 2010 a 2019, com maior ou menor contribuição de cada indutor principal na oscilação observada. Contudo, chama a atenção a redução do gasto em alguns anos, induzida principalmente pela diminuiçáo da quantidade de medicamentos adquirida em dois anos consecutivos, o que pode resultar em queda da disponibilidade desses produtos no Sistema Único de Saúde (SUS).

Palavras-chave: gastos em medicamentos; indutores do gasto; preparaçóes farmacêuticas; Sistema Único de Saúde; gastos em saúde.

\section{ABSTRACT}

The objective of this text is to analyze the contribution of the main drivers of the direct expenditure of the Ministry of Health (MS) in medicines that are part of the list of Pharmaceutical Assistance Programs (PAP) from 2010 to 2019. Acquisitions data included in the information system called SIASG were used. The drugs were categorized according to the ATC/DDD (Anatomical Therapeutic Chemical Classification System/ Defined Daily Doses) of the World Health Organization. The physical units of purchase of the products were transformed into the number of defined daily doses (DDD) for each drug. And the unit price was converted to price per DDD. With the support of RStudio software version 1.3.1056 and the statistical package IndexNumR, the contribution of the main drivers of expenditure on medicines was measured: price, quantity, and residuals (therapeutic choices). The results show a wide variation in the expenditure of the Ministry of Health on medicines in the list of PAP from 2010 to 2019, with a greater or lesser contribution of each main driver in the observed oscillation. However, 
it is important to note the expenditure reduction in some years, mainly driven by a decrease in the quantity of drugs purchased in two consecutive years, which may result in a drop in the availability of these products in the Unified Health System.

Keywords: drug expenditure; drivers; pharmaceutical preparations; Unified Health System; health expenditures. 


\section{INTRODUÇÃO}

As preocupaçóes dos gestores públicos e o interesse da sociedade de uma forma geral a respeito do gasto em medicamentos têm crescido no Brasil, especialmente, a partir do fim dos anos 1990, quando foi aprovada a Política Nacional de Medicamentos - PNM (Brasil, 1998). Com a publicação da Política Nacional de Assistência Farmacêutica - PNAF (Brasil, 2004), intensificou-se a implementação de programas nesta área, destinados a ampliar o acesso da população a medicamentos por meio do Sistema Único de Saúde (SUS), e ampliaram-se os gastos do governo com esses produtos.

Essa não é uma questão apenas de interesse nacional, mas também um tema que tem figurado na agenda internacional há algumas décadas, em virtude da tendência de aumento das despesas em medicamentos acima do aumento das despesas em saúde. Ainda que nos últimos anos diversos países, principalmente os de alta renda, tenham implementado políticas para a contenção dos gastos em medicamentos e essas políticas tenham contribuído para a desaceleração desse aumento, o consumo desses produtos continua subindo e induzindo o crescimento das despesas (Belloni, Morgan e Paris, 2016). Ademais, os elevados preços dos novos medicamentos geram grandes desafios aos sistemas de saúde em todo o mundo, independentemente da renda do país (Belloni, Morgan e Paris, 2016; Bermudez, Luiza e Silva, 2020). Entre países de alta renda que possuem sistema universal de saúde, significativas diferenças de gastos em medicamentos utilizados na atenção primária são explicadas mais por fatores que afetam os custos dos tratamentos do que os que afetam os volumes consumidos (Morgan, Leopold e Wagner, 2017).

Na média, o gasto em medicamentos de países da Organização para a Cooperação e o Desenvolvimento Econômico (OCDE) girava em torno de $20 \%$ do gasto em saúde em 2013, quando alcançou cerca de US\$ 800 bilhôes (Belloni, Morgan e Paris, 2016). Para o conjunto de países constituído por Alemanha, Espanha, França, Itália e Reino Unido, a taxa de crescimento do gasto em medicamentos foi de 2,5\% entre 2010 e 2016, considerando os descontos praticados no setor farmacêutico. Projeçóes mais realistas ${ }^{1}$ para os gastos desse conjunto de países são de aumento de $1,5 \%$ das despesas entre 2016 e 2021 (Espin et al., 2018). A previsão, portanto, ainda que menor do que a realizada em outras projeçôes que utilizam os preços regulados como base, é de aumento

1. Considerando não os preços regulados, mas os preços praticados no mercado, que são menores que os primeiros em virtude da incidência de descontos. 
dos gastos mesmo em países que possuem sistema de saúde bastante consolidado e com acesso ampliado da população a medicamentos.

Em países de renda média, além da pressão exercida pelos preços dos novos medicamentos, os gastos podem ser fortemente impulsionados pela demanda, uma vez que várias necessidades de saúde possivelmente ainda não foram satisfeitas. Também podem ser induzidos pela regulação insuficiente do mercado farmacêutico e da oferta no setor público. Por exemplo, na China, o gasto total em medicamentos foi, em média, de $45,7 \%$ do gasto total em saúde no período de 1990 a 2009 e uma explicaçáo apresentada para essa elevada participaçáo foi a de irracionalidade do uso de medicamentos naquele país (Shi, Yang e Cheng, 2014). Dados de Taiwan também sinalizam para este mesmo problema. O crescimento da despesa foi de 57\% entre 1997 e 2001, havendo na lista de medicamentos sujeitos a reembolso pelo governo (lista positiva) mais de 21 mil produtos (Hsieh e Sloan, 2008).

No Brasil, a participação do gasto em medicamentos no gasto total em saúde variou de 22,4\% em 2010 para 18,4\% em 2017, com elevado pagamento direto do bolso. Em 2017, as famílias arcaram com $92 \%$ da despesa de consumo final de medicamentos do país (IBGE, 2019). Esse fato torna o monitoramento do gasto público em medicamentos particularmente importante, pois a expectativa é de que ele promova a ampliaçáo da oferta desses produtos pelo SUS e com isso reduza o desembolso direto das famílias, aliviando especialmente o orçamento daquelas de menor renda.

Quanto à participação das esferas de governo no financiamento da oferta de medicamentos, houve crescimento da participação federal, com ampliação das aplicaçóes diretas (gasto direto) do MS. Ou seja, a participação federal aumentou não apenas o financiamento das despesas desses produtos, mas também a sua aquisição para distribuição às secretarias de saúde, especialmente dos estados e do Distrito Federal. As aplicaçóes diretas passaram de $\mathrm{R} \$$ 4,3 bilhóes em 2010 para $\mathrm{R} \$ 13,2$ bilhóes em 2016, em valores constantes, o que equivale a um crescimento de $207 \%$ nesse período (Vieira, 2018). Entre 2010 e 2017, a participaçáo federal no financiamento do gasto em medicamentos do SUS passou de $71 \%$ para $85 \%$. Esse período foi marcado pela centralizaçáo da compra de medicamentos no MS e responsabilização do órgão pela aquisição da maior parte dos novos medicamentos incorporados (Vieira, 2019).

No contexto nacional, para gerar informações sobre as despesas em medicamentos do SUS, sistemas de informação orçamentários provêm dados que facilitam a sua produção, a exemplo do Siga Brasil para o orçamento federal, que é mantido pelo 
Senado; e do Sistema de Informações sobre Orçamentos Públicos em Saúde (Siops) para o orçamento dos estados, do Distrito Federal e dos municípios, que está sob a gestão do MS. Os dados obtidos a partir desses sistemas possibilitam a realizaçáo de estudos específicos sobre a evolução do gasto do ponto de vista orçamentário (Vieira, 2018) e a elaboração de estatísticas segundo diferentes metodologias de contas de saúde - conta-satélite de saúde (IBGE, 2019) e sistema de contas de saúde (Brasil, 2018).

Ainda que extremamente úteis, essas informações não esclarecem questôes importantes sobre os fatores que determinam o comportamento do gasto de um ano para o outro. A ampliaçáo do gasto não significa necessariamente ampliação da cobertura populacional, pois pode ocorrer concentração da alocação de despesas para poucas pessoas, o que pode acontecer em razáo da judicialização da saúde e de outros fatores. Assim como pode ocorrer concentraçáo do gasto em produtos de alto preço, podendo ser fruto de um processo ainda deficitário de avaliação da incorporação tecnológica e de regulação econômica do mercado. Da mesma forma, uma redução do gasto não implica necessariamente redução da cobertura, pois os preços dos produtos podem ter reduzido; a lista de medicamentos pode ter sido alterada de um ano para outro, sem prejuízo para a terapêutica; e os protocolos de uso de medicamentos, assim como outras medidas para racionalizar o uso dos produtos farmacêuticos podem ter sido implementados, contribuindo para maior eficiência na alocação dos recursos (Vieira, 2019). Por isso, investigaçôes sobre os fatores que induzem o aumento ou a redução do gasto precisam ser realizadas, assim como estudos para a identificação das causas da mudança desses fatores.

No tocante à identificação da contribuição dos fatores, o conhecimento sobre o papel de cada um deles pode subsidiar tanto os gestores públicos responsáveis pela implementação da PNAF na tomada de decisão, para que os objetivos da política sejam alcançados, quanto a sociedade, para o efetivo exercício do controle social sobre os rumos da política. Para o contexto nacional, não foram identificados estudos sobre os indutores do gasto do MS em medicamentos. Encontrou-se apenas um trabalho publicado que analisa os indutores do gasto de órgáos vinculados ao governo federal em imunossupressores entre 2010 e 2015 (Alves et al., 2018).

Desse modo, considerando a necessidade de se avançar no preenchimento dessa lacuna de informação e a relevância do governo federal para a oferta de produtos farmacêuticos no SUS, o objetivo deste texto é analisar a contribuição dos principais indutores do gasto direto do MS em medicamentos que integram a lista dos componentes da Assistência Farmacêutica (AF) no período de 2010 a 2019. 
Após esta introdução, apresenta-se na segunda seção uma revisão da literatura sobre os determinantes e indutores do gasto em medicamentos, com especial destaque para a discussão metodológica sobre como medir a contribuição de cada um deles. Os métodos adotados na realização deste estudo são descritos na terceira seção. A seguir, na quarta seçáo, os resultados são apresentados e a discussão sobre eles é feita na sequência de sua apresentação. Por fim, uma síntese dos principais achados é apresentada na quinta seção, das conclusôes.

\section{DETERMINANTES E INDUTORES DO GASTO EM MEDICAMENTOS}

\subsection{Determinantes e indutores do gasto}

Determinantes do gasto em medicamentos são fatores que definem a despesa com esses produtos, como a estrutura etária da populaçáo, a quantidade e o tipo de medicamentos utilizados, o nível dos preços, entre outros. Os determinantes se transformam em indutores do gasto quando eles promovem uma mudança nas despesas entre dois períodos, para mais ou para menos (Canada, 2013).

São três os indutores principais do gasto em medicamentos: o preço, a quantidade e as escolhas terapêuticas, que são chamadas de resíduos (Gerdtham et al., 1998; Mousnad, Shafie e Ibrahim, 2014). O agrupamento desses indutores pode ser feito com pequenas modificaçóes, como proposto por um grupo de especialistas canadenses (Canada, 2013), mas, na prática, os indutores principais se resumem às três categorias mencionadas anteriormente (Belloni, Morgan e Paris, 2016), sendo particularmente importantes para o aumento do gasto em medicamentos as variaçóes de quantidade e das escolhas terapêuticas (Mousnad, Shafie e Ibrahim, 2014). Apresenta-se a seguir a categorização utilizada pelos pesquisadores canadenses.

1) Efeito preço, que se subdivide em:

a) efeito da mudança do preço: capta alteraçóes nos preços dos produtos; e

b) efeito da substituição dos medicamentos de marca por medicamentos genéricos: capta alteraçóes decorrentes da substituição de medicamentos mais caros, de marca, por suas versôes genéricas.

2) Efeito do volume (quantidade), que se subdivide em:

a) efeito do volume de prescrições: capta alteraçōes do número de prescriçōes realizadas; 
b) efeito do tamanho das prescrições: capta alteraçóes do número médio de unidades de um medicamento dispensado; e

c) Efeito das apresentações: capta alterações na utilização de diferentes concentraçóes e formulações de um mesmo fármaco (princípio-ativo).

3) Efeito do mix de medicamentos, que se subdivide em:

a) efeito dos medicamentos existentes: capta alterações de uso de medicamentos entre várias classes e subclasses terapêuticas;

b) efeito da exclusão de medicamentos: capta alterações em razão da exclusão de itens; e

c) efeito da incorporação de medicamentos: capta alterações decorrentes da inclusão de novos medicamentos.

4) Efeito demográfico, que pode ser medido de forma separada do efeito do volume, quando há informação suficiente para tanto. Subdivide-se em:

a) efeito da população: capta o tamanho da população; e

b) efeito do envelhecimento: capta alterações na estrutura etária da população.

Nota-se, a partir desse agrupamento, que os indutores podem ser divididos entre principais e secundários. Os primeiros são os três citados antes (preço, quantidade e escolhas terapêuticas/resíduo/mix de medicamentos). Os secundários influenciam os principais e podem ser observados no agrupamento apresentado anteriormente. Por exemplo, o tamanho da prescrição é um indutor secundário que influencia a quantidade utilizada de medicamentos, que é um indutor primário. A mensuração da contribuição dos indutores secundários está condicionada à disponibilidade de informações nas bases de dados de registros administrativos.

Belloni, Morgan e Paris (2016) classificaram os fatores que influenciam atualmente os três indutores principais do gasto em medicamentos nas seguintes categorias.

1) Fatores relacionados à demanda por medicamentos:

a) induzem o aumento do gasto com efeito sobre a quantidade: tamanho da população e composição demográfica; emergência de novas doenças; prevalência e gravidade das doenças; mudanças nos protocolos e/ou prática dos médicos; e

b) induzem o aumento do gasto com efeito sobre as escolhas terapêuticas: mudanças nos protocolos e/ou práticas dos médicos.

2) Fatores relacionados à dinâmica do mercado farmacêutico:

a) induzem o aumento do gasto com efeito sobre a quantidade: introdução de novos medicamentos; 
b) induzem a redução do gasto com efeito sobre os preços: introdução de novos medicamentos, se promovem competição no mercado; expiração de patentes e introdução de medicamentos genéricos;

c) induzem o aumento do gasto com efeito sobre as escolhas terapêuticas: introdução de novos medicamentos; e

d) induzem a redução do gasto com efeito sobre as escolhas terapêuticas: expiração de patentes, se há mudança da prescrição para produtos não protegidos por patentes.

3) Fatores relacionados às políticas farmacêuticas:

a) induzem o aumento do gasto com efeito sobre a quantidade: expansão da cobertura;

b) induzem a redução do gasto com efeito sobre os preços: cortes de preços e mudanças na distribuição das margens de lucro e nos tributos; políticas de preço de referência; e

c) induzem a redução do gasto com efeito sobre as escolhas terapêuticas: promoção do uso racional de medicamentos.

\subsection{Mensuração da contribuição dos indutores para a variação do gasto}

A mensuração da contribuição de cada determinante para a variação do gasto em medicamentos tem sido realizada por meio da aplicação de análises de decomposição (Canada, 2013; Mousnad, Shafie e Ibrahim, 2014; Belloni, Morgan e Paris, 2016). Essas análises são divididas em dois grupos, decomposição do índice e decomposição da estrutura, e se fundamentam na teoria dos números-índices, ${ }^{2}$ a qual tradicionalmente diz respeito à medida da mudança agregada das variáveis preço e quantidade de determinado produto ou serviço (Boer e Rodrigues, 2019).

No século XIX, as mais importantes contribuiçôes ao desenvolvimento dos números-índices foram dadas por Laspeyres em 1871 e Paasche em 1874. No século XX, em 1922, Fisher propôs uma abordagem metodológica híbrida dos métodos idealizados pelos dois primeiros economistas. Em termos práticos, as diferenças entre os três métodos são as seguintes: i) Laspeyres considerou uma cesta de produtos no período-base, calculou o gasto total nesse período e no período de comparação, e produziu um índice de preços que é a razão entre o total de despesas no período de comparação e o total de despesas

2. Um exemplo corriqueiro de aplicação da teoria dos números-índices envolve o cálculo dos índices de inflação, que são mensurados com o objetivo de se obter um único número que represente a variação dos preços de uma cesta de bens e/ou serviços entre determinados pontos no tempo, com ou sem ponderação pelas quantidades consumidas. Para uma explicação básica sobre os números-índices e os índices de preços, ver: <https://bit.ly/3diMl2c>. Acesso em: 12 out. 2020. 
no período-base; ii) Paasche, por sua vez, escolheu a cesta do período de comparação em vez do período-base e manteve os demais procedimentos metodológicos; e iii) Fisher propôs como novo índice de preço a média geométrica dos índices de preço de Laspeyres e Paasche (Boer e Rodrigues, 2019). Houve outras contribuiçôes metodológicas ao cálculo do índice de preços, mas essas três abordagens são as mais conhecidas e utilizadas.

Inicialmente, a teoria dos números-índices fundamentou o desenvolvimento das metodologias mencionadas para mensuração do índice dos preços de uma cesta de bens e/ou serviços entre dois períodos, com ponderação pelas quantidades. $\mathrm{O}$ interesse principal nesses casos é o cálculo da variação dos preços. Posteriormente, essas mesmas metodologias passaram a ser utilizadas nas análises de decomposição do gasto, a fim de se estimar a contribuição do preço e da quantidade na variaçáo das despesas com uma cesta de bens e/ou serviços entre dois períodos. Neste caso, interessa conhecer a magnitude da contribuiçáo de cada variável para a mudança da despesa.

Na decomposição do gasto pelo método de Laspeyres, assume-se que o gasto $(G)$ é igual ao produto do preço $(P)$ e da quantidade $(Q)$ de determinado bem ou serviço, ou seja, $G=P$. $Q$. Considerando o comportamento das variáveis $P$ e $Q$ para um único produto em dois períodos (tempos), período-base $\left(T_{0}\right)$ e período de comparaçáo $\left(T_{1}\right)$, três efeitos são identificados (Canada, 2013):

- efeito preço: mede o impacto no gasto $(G)$ da mudança do preço $(P)$ entre o período-base e o período de comparaçáo, mantendo constante a quantidade $(Q)$ do periodo-base: $\left[\left(P_{1}-P_{0}\right) \cdot Q_{0}\right]$

- efeito quantidade: mede o impacto no gasto $(G)$ da mudança da quantidade $(Q)$ entre o período-base e o período de comparaçáo, mantendo constante o preço $(P)$ do periodo-base: ; $\left[\left(Q_{1}-Q_{0}\right) \cdot P_{0}\right] \mathrm{e}$

- efeito cruzado: mede o impacto no gasto $(G)$ da interação da mudança da variável preço $(P)$ e da variável quantidade $(Q)$ entre os dois períodos: $\left[\left(P_{1}-P_{0}\right) \cdot\left(Q_{1}-Q_{0}\right)\right]$.

Assim, a decomposição do gasto pelo método de Laspeyres para um produto é dada por:

$$
G_{1}-G_{0}=\left[\left(P_{1}-P_{0}\right) \cdot Q_{0}\right]+\left[\left(Q_{1}-Q_{0}\right) \cdot P_{0}\right]+\left[\left(P_{1}-P_{0}\right) \cdot\left(Q_{1}-Q_{0}\right)\right] .
$$

Recomenda-se que o método de Laspeyres seja utilizado quando se deseja medir o efeito dos preços e das quantidades no gasto, separado do efeito cruzado ${ }^{3}$, avaliando

3. 0 efeito cruzado resulta de mudanças simultâneas nas variáveis preço e quantidade. 
cada indutor do gasto a partir da manutenção dos outros fatores no valor do período-base $\left(T_{0}\right)$ (Canada, 2013).

O método de Paasche, diferentemente, avalia cada indutor do gasto considerando os valores dos outros fatores no período de comparação $\left(T_{1}\right)$. Assim, tem-se (Canada, 2013):

- efeito preço: mede o impacto no gasto $(G)$ da mudança do preço $(P)$ entre o período-base e o período de comparaçáo, mantendo constante a quantidade $(Q)$ do período de comparação: $\left[\left(P_{1}-P_{0}\right) \cdot Q_{1}\right]$;

- efeito quantidade: mede o impacto no gasto $(G)$ da mudança da quantidade $(Q)$ entre o período-base e o período de comparação, mantendo constante o preço $(P)$ do período de comparação: ; $\left[\left(Q_{1}-Q_{0}\right) \cdot P_{1}\right]$ e

- efeito cruzado: mede o impacto no gasto $(G)$ da interação da mudança da variável preço $(P)$ e da variável quantidade $(Q)$ entre os dois períodos: $\left[\left(P_{1}-P_{0}\right) \cdot\left(Q_{1}-Q_{0}\right)\right]$.

Assim, a decomposição do gasto pelo método de Paasche para um produto é dada por: $G_{1}-G_{0}=\left[\left(P_{1}-P_{0}\right) \cdot Q_{1}\right]+\left[\left(Q_{1}-Q_{0}\right) \cdot P_{1}\right]-\left[\left(P_{1}-P_{0}\right) \cdot\left(Q_{1}-Q_{0}\right)\right]$

Note-se que no método de Laspeyres o efeito cruzado precisa ser somado aos demais efeitos para cálculo da variação do gasto, enquanto no método de Paasche ele é subtraído. Isso ocorre porque no segundo método avaliam-se os efeitos diretos do preço e da quantidade nos valores do período de comparação e esses efeitos incluem o impacto das interaçôes das mudanças de preço e quantidade. Dessa forma, o efeito cruzado deve ser subtraído para evitar dupla contagem (Canada, 2013).

Considerando as perspectivas dos dois métodos, diz-se que o de Laspeyres olha para a frente e o de Paasche olha para trás. $\mathrm{O}$ primeiro responde à pergunta "quanto maior foi a despesa deste ano simplesmente por causa dos preços mais altos?" e o segundo à questão "quanto mais baixa teria sido a despesa este ano a preços do ano passado?" (Canada, 2013, p. 9).

Como os métodos de Laspeyres e Paasche assumem diferentes perspectivas, eles respondem a distintas questóes, o que resulta em estimativas diferentes para os indutores do gasto. Além disso, nenhum dos dois métodos realiza a atribuição completa do gasto para cada indutor, dada a existência do efeito cruzado (para cada produto), que é medido de forma separada e não é atribuído aos indutores individualmente (Canada, 2013). 
Para resolver essas limitaçôes, Fisher propôs que a variação do gasto seja calculada pela média geométrica dos índices de Laspeyres e de Paasche. Trata-se de uma média simétrica homogênea que satisfaz o teste de reversão do tempo. ${ }^{4}$ Ademais, o efeito cruzado é dividido entre os indutores do gasto de forma igual, o que faz com que o método tenha a propriedade da proporcionalidade, ou seja, o produto dos índices de preço e de quantidade é igual ao índice do gasto (Canada, 2013; Boer e Rodrigues, 2019). Assim, tem-se para um produto:

$$
\begin{aligned}
& G_{1}-G_{0}=\left\{\left[\left(P_{1}-P_{0}\right) \cdot Q_{0}\right]+\left[1 / 2 \cdot\left(P_{1}-P_{0}\right) \cdot\left(Q_{1}-Q_{0}\right)\right]\right\}+ \\
& \left\{\left[P_{0} \cdot\left(Q_{1}-Q_{0}\right)\right]+\left[1 / 2 \cdot\left(P_{1}-P_{0}\right) \cdot\left(Q_{1}-Q_{0}\right)\right]\right\}
\end{aligned}
$$

O método de Fisher tem sido frequentemente utilizado na mensuração da contribuição de cada indutor na variação do gasto em medicamentos (Morgan, 2002; 2004; 2005; Morgan, Leopold e Wagner, 2017; Soppi et al., 2018). Mas recomenda-se atençáo para o fato de que é razoável utilizá-lo apenas nos casos em que os indutores mudam independentemente um do outro, uma vez que o efeito cruzado é atribuído igualmente entre eles. Por exemplo, quando a quantidade utilizada do medicamento independe do preço (Canada, 2013).

Os três métodos mencionados são muito úteis para a identificação da contribuição dos determinantes na variação do gasto em medicamentos, entretanto, Morgan (2002) chama a atenção para o fato de que eles se fundamentam nos pressupostos-padrão da economia. Segundo esse autor, embora esses pressupostos ajudem a simplificar a análise da tendência do gasto, não se pode assumir que a quantidade e a qualidade do resultado são proporcionais ao custo dos produtos farmacêuticos prescritos, uma vez que esses produtos não são como outras commodities. No mercado farmacêutico, há assimetria de informação, tomada de decisão imperfeita e incentivos financeiros não padronizados. Essas características fazem com que o modelo de comportamento do consumidor que garante uma relaçáo entre o preço relativo e o valor relativo dos bens adquiridos não se aplique a esses produtos.

4. A reversão temporal (simetria) é uma propriedade do índice de preços. Quando o índice de preço (quantidade) para o período-base em relação ao período de comparação é igual ao recíproco do índice de preço (quantidade) para o período de comparação em relação ao período-base, diz-se que o índice tem a propriedade da reversão temporal (Boer e Rodrigues, 2019). 
Outra questão a respeito da aplicação dos métodos de Laspeyres, Paasche e Fisher para a estimativa do efeito dos indutores do gasto em medicamentos envolve a cesta de produtos. Os três métodos, considerando as diferenças apontadas, possibilitam a mensuração dos efeitos da variação dos preços e das quantidades na variação do gasto para uma cesta fixa de produtos entre dois períodos (White, 2020a). Na prática, a oferta de medicamentos pelos sistemas ou pelas organizaçóes de saúde varia frequentemente. Alguns medicamentos podem ser excluídos da lista de produtos disponibilizados e outros podem ser incorporados a essa lista entre os períodos analisados. Assim, a simples mensuração dos efeitos dos preços e da quantidade dos produtos existentes nos dois períodos não explicará totalmente a variação do gasto em medicamentos, se novos produtos foram incorporados e outros foram excluídos. Ademais, há mudanças no uso dos medicamentos que pertencem à mesma classe terapêutica ${ }^{5}$ e estão disponíveis nos dois períodos analisados.

Por essa razão, Gerdtham et al. (1998) propuseram computar o que eles chamam de resíduo, o qual reflete as mudanças no gasto em medicamentos que é resultante de alteraçóes nos padróes de tratamento. Os autores esclarecem que o cálculo do resíduo é importante porque é difícil construir um índice de quantidade que consiga captar adequadamente as mudanças na qualidade dos produtos farmacêuticos. Além disso, os índices de preço não refletem alteraçóes no preço que resultam de mudanças no consumo dos medicamentos entre dois períodos e, assim, pode ocorrer sobrestimação ou subestimação do preço real por causa da introdução de novos medicamentos e de mudanças no padrão de tratamento. Com isso, um aumento real no gasto em medicamentos não corresponde a um aumento no índice relativo de preços no varejo multiplicado por algum índice de quantidade.

5. Se os medicamentos pertencem à mesma classe terapêutica, eles possuem a mesma indicação terapêutica. Na maioria dos casos, eles são substitutos uns dos outros. Mas, para alguns grupos de pacientes ou pacientes específicos, pode ocorrer de a substituição não poder ser feita por contraindicação ou intolerância do paciente ao medicamento. 
Ademais, Gerdtham et al. (1998) sugerem que a quantidade dos medicamentos seja medida em número de doses diárias definidas (DDD), que é a dose de manutenção média assumida por dia para um medicamento usado por adultos na sua indicação principal (WHO, 2018). Ao medir a quantidade em números de DDD, o resíduo captará a mudança no preço geral por DDD que não é devida à inflação dos preços de cada medicamento, mas por alteraçáo no uso de produtos pertencentes à mesma classe terapêutica. Dessa forma, refletirá mudanças no gasto em medicamentos resultantes de mudanças nos padróes de tratamento.

Segundo esses autores, há duas alteraçóes nos padróes de tratamento que afetam o resíduo: i) troca de um medicamento por outro, com manutenção da quantidade de DDDs consumidas; e ii) troca de um medicamento por outro, com aumento da quantidade (número de pacientes tratados). No primeiro caso, se o tratamento que substituiu o anterior for mais caro, haverá aumento do resíduo, e se for mais barato, ocorrerá sua redução. No segundo caso, o impacto sobre o resíduo e, consequentemente, sobre o gasto, também depende do preço do tratamento que substituiu o anterior, mas para que seja negativo, o seu preço deverá ser mais baixo que o do tratamento anterior, o suficiente para suplantar o efeito do aumento da quantidade de pacientes tratados.

Gerdtham et al. (1998) definiram a seguinte fórmula para cálculo do resíduo, na forma de um índice, considerando a quantidade de tratamentos com um medicamento $A\left(Q_{A 0}\right)$ e seu preço $\left(P_{A 0}\right)$ no período-base e a quantidade de tratamentos com um medicamento $B\left(Q_{B I}\right)$ e seu preço $\left(P_{B I}\right)$ no período de comparaçáo:

$$
\text { Resíduo }=\left[\frac{\left(Q_{A 0}+Q_{B 0}\right)}{\left(Q_{A 1}+Q_{B 1}\right)}\right] \cdot\left\{\frac{\left[\left(P_{A 1} \cdot Q_{A 1}\right)+\left(P_{B 1} \cdot Q_{B 1}\right)\right]}{\left[\left(P_{A 1} \cdot Q_{A 0}\right)+\left(P_{B 1} \cdot Q_{B 0}\right)\right]}\right\}
$$

Para facilitar o entendimento sobre o efeito captado pelo resíduo, a tabela 1 apresenta as situaçóes que o afetam e alguns exemplos com base no trabalho desses autores. 


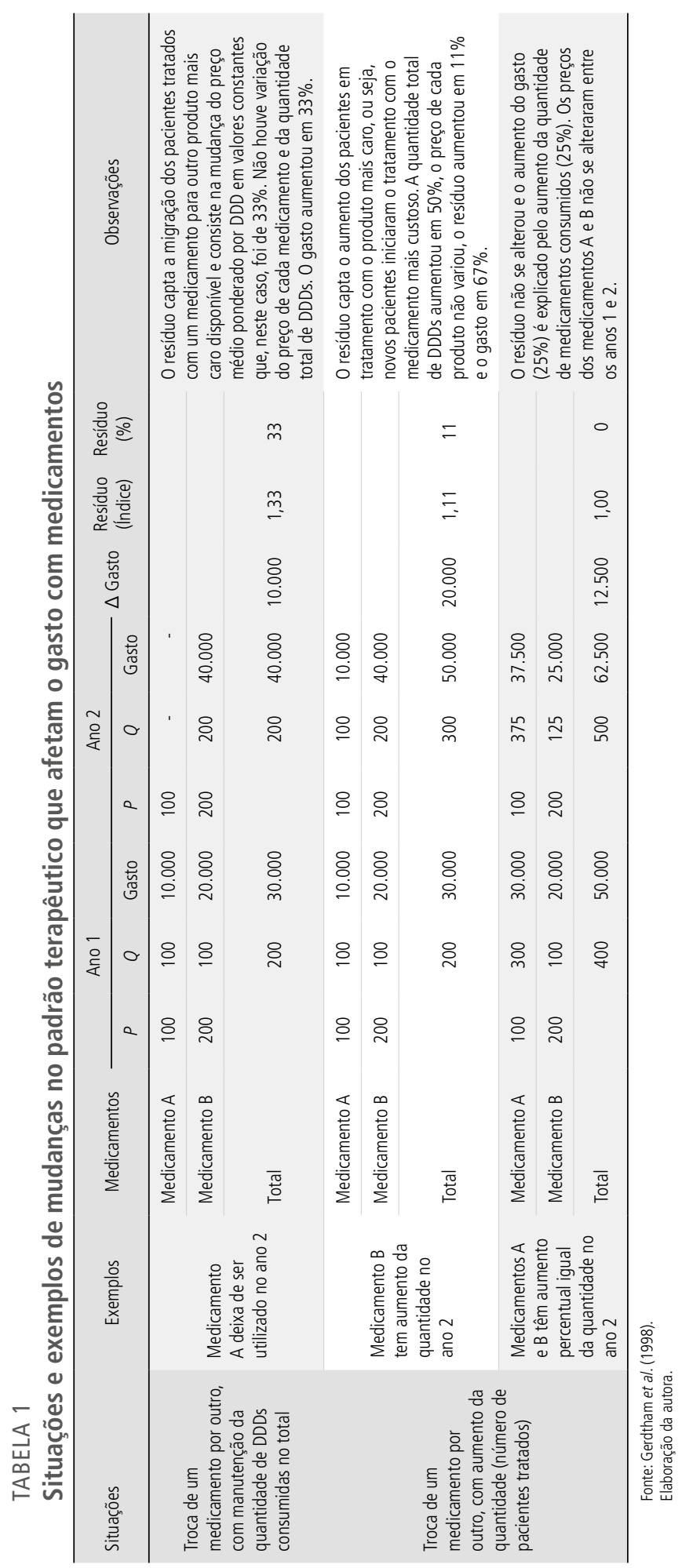

18 
Nessa ótica, o padrão de tratamento diz respeito a mudanças que ocorrem no uso de medicamentos que pertencem à mesma classe terapêutica, o que depende obviamente dos medicamentos que a compóem. Por exemplo, considerem-se os inibidores da enzima conversora da angiotensina (ECA), utilizados no tratamento da hipertensão arterial. Assume-se, hipoteticamente, que na lista do sistema de saúde no período-base eram disponibilizados os medicamentos captopril e enalapril. No período de comparação, estavam disponíveis os medicamentos enalapril e ramipril. Houve, entáo, substituição do captopril pelo ramipril, produto mais caro. Pode ocorrer manutençáo da quantidade de tratamentos com inibidores da ECA, havendo direcionamento para o produto com preço maior, ou pode haver aumento do número de pacientes tratados com medicamentos dessa classe, ramipril, por exemplo. O resíduo capta o efeito dessas mudanças e, portanto, é uma variável que se relaciona com as escolhas terapêuticas, sendo influenciado não apenas pelas alteraçóes envolvendo o uso de medicamentos disponíveis, mas também pela incorporação de medicamentos.

Destaca-se que para a estimativa do efeito do resíduo, a quantidade física de cada medicamento deve ser convertida para uma medida que traduza o volume de tratamentos oferecidos (números de DDDs, por exemplo), visto que a quantidade necessária para que se tenha um tratamento por dia pode variar de produto para produto. Para ilustrar, o tratamento diário com alguns medicamentos é feito com o uso de um comprimido por dia, enquanto com outros são necessários dois ou mais comprimidos diários. Ademais, a utilização do número de DDDs como variável de quantidade em vez das unidades físicas se justifica porque um mesmo fármaco pode ser comercializado em diferentes concentrações e apresentaçóes, resultando em distintos produtos acabados (medicamentos), sendo que as unidades físicas geralmente não são cumulativas (Canada, 2013). Considerá-las distorceria a informação. Dessa forma, o objetivo de uso da DDD é obter uma medida quantitativa da aquisição por princípio-ativo (Gerdtham et al., 1998), a partir da padronização dos produtos com diferentes formulaçóes, concentraçóes e tamanhos de embalagem (Soppi et al., 2018). As vantagens do uso da DDD são: i) permite comparaçôes entre países e diferentes relações de medicamentos; ii) para doenças crônicas, ela representa uma aproximação à prevalência de tratamentos; iii) também é um padrão para a comparação do comportamento dos médicos em diferentes países; e iv) ela descreve o perfil terapêutico para vários grupos de medicamentos (Addis e Magrini, 2002).

Assim, conforme proposto por Gerdtham et al. (1998), o índice do gasto em medicamentos entre dois períodos pode ser calculado pelo produto dos índices de preço, da quantidade e do resíduo, como segue:

$$
\mathrm{I}_{\mathrm{G}}=\mathrm{I}_{\mathrm{P}} \cdot \mathrm{I}_{\mathrm{Q}} \cdot \mathrm{I}_{\mathrm{R}}
$$


Em que:

- $I_{G}=$ índice do gasto em medicamentos;

- $I_{P}=$ índice dos preços por tratamento/dia;

- $I_{Q}=$ índice das quantidades (tratamentos diários); e

- $I_{R}=$ índice dos resíduos.

Os índices de preço e quantidade refletem a variação nos preços e nas quantidades dos produtos existentes nos dois períodos em análise; e o índice dos resíduos evidencia o efeito do padrão de tratamento sobre o gasto. Essa mesma abordagem metodológica é adotada por Morgan (2004), que propóe decompor cada um dos indutores do gasto da fórmula mencionada $\left(I_{G}=I_{P} \cdot I_{Q} \cdot I_{R}\right)$ em outros dois, caso haja informação nas bases de dados disponíveis para tanto: i) decomposição do $I_{P}$ no índice do uso de genéricos $\left(I_{U G}\right)$ e no índice dos preços dos demais medicamentos $\left(I_{P M}\right)$, de forma que: $I_{P}=I_{U G} I_{P M^{\prime}}$; ii) decomposição do $I_{Q}$ no índice de volume de prescriçôes $\left(I_{V P}\right)$ e no índice do tamanho das prescriçóes $\left(I_{T P}\right)$, tal que: $I_{Q}=I_{V P} I_{T P}$; e iii) decomposiçáo do $I_{R}$ no índice das classes terapêuticas $\left(I_{C T}\right)$ e no índice dos medicamentos em cada classe terapêutica $\left(I_{M C T}\right)$, de forma que: $I_{R}=I_{C T} I_{M C T}$. Cada índice reflete as mudanças ocorridas entre o período-base e o de comparação para cada um dos indutores do gasto.

Do ponto de vista prático, os cálculos dos $I_{G}, I_{P}$ e $I_{Q}$ podem ser feitos com a utilização de funçôes disponíveis em softwares de estatística, o que facilita em muito o trabalho, considerando que a análise da contribuição dos indutores do gasto será realizada não apenas para um medicamento, mas também para uma relação mais ou menos extensa desses produtos. Para a mensuração do $I_{P}$ e do $I_{Q}$, esses softwares geralmente dispóem de funçóes que aplicam os métodos de Laspeyres, Paasche, Fisher, entre outros, no cálculo dos índices. Na escolha do método, é preciso ter em mente que se o objetivo é decompor o gasto, mensurando-se a contribuição dos três indutores principais $(P, Q$ e $R$ ), entre os métodos citados, o de Fisher é o mais adequado, porque o efeito cruzado das variaçóes simultâneas no preço e na quantidade de cada item que se repete nos dois períodos é distribuído igualmente entre os indutores $P$ e $Q$, havendo atribuição completa do gasto com o item (Canada, 2013). O $I_{G}$ é calculado considerando o gasto total em cada período, o de base e o de comparação $\left(I_{G}=G_{I} / G_{0}\right)$. Com os valores do $I_{G}, I_{P}$ e $I_{Q}$, é simples calcular o $I_{R}$ considerando a fórmula proposta por Gerdtham et al. (1998), dado que:

$$
I_{R}=\frac{I_{G}}{\left(I_{P} \cdot I_{P}\right)}
$$


Dessa forma, obtêm-se os índices que refletem a contribuição dos três indutores principais na variaçáo do gasto em medicamentos, produzindo-se informaçáo relevante para os tomadores de decisão na saúde, especialmente no tocante à política de assistência farmacêutica.

Os indutores principais podem ser decompostos em outros indutores, como mencionado anteriormente. Nesse caso, o Conselho de Revisão de Preços de Medicamentos Patenteados, ${ }^{6}$ que é uma agência federal do Canadá, publicou relatório metodológico no qual se encontra detalhamento das fórmulas utilizadas (Canada, 2013). Não se identificaram funcionalidades prontas em softwares de estatística que contemplem essa metodologia. É provável que a realização dos cálculos propostos demande o desenvolvimento de programação específica e, portanto, sua implementação seja mais complexa.

Assim, apresentada esta breve revisão da literatura sobre os indutores do gasto em medicamentos e as metodologias para a estimativa da contribuição de cada um deles para a variação desse gasto, na próxima seção, descrevem-se os métodos adotados na realização deste estudo.

\section{MÉTODOS}

\subsection{Fontes de informação e dados utilizados}

Foram utilizadas informaçóes de compras do MS do período de 2010 a 2019, realizadas por meio do departamento de logística, provenientes do Siasg. ${ }^{7}$ Este sistema auxilia o Sistema de Serviços Gerais (Sisg) do governo federal e possui vários módulos de compras públicas de uso obrigatório por todas as unidades integrantes dessa esfera de governo. Destacam-se entre esses módulos o Catálogo de Materiais (Catmat), que contempla o padráo descritivo para bens adquiridos pelo governo, e o portal de compras governamentais, utilizado para a operacionalização das licitaçóes. ${ }^{8}$

Foram obtidas as seguintes variáveis do Siasg: Código BR (código constante no Catmat para cada medicamento), descrição (fármaco, ${ }^{9}$ concentração e forma

6. A sigla em inglês é Patented Medicine Prices Review Board.

7. Os dados foram extraídos e disponibilizados por técnico do MS.

8. Para mais informações sobre o Siasg, ver: <http://bit.ly/3c160Ub>. Acesso em: 8 ago. 2020.

9. 0 fármaco é o princípio-ativo ou insumo farmacêutico ativo dos medicamentos. 
farmacêutica), unidade de fornecimento, ano, modalidade da compra, objeto, justificativa para dispensa/inexigibilidade de licitação, quantidade, valor unitário e valor total.

As aquisições do MS foram classificadas conforme grupos de destinação dos medicamentos da seguinte forma.

1) Componentes da AF (SUS): abrange os produtos incluídos na lista dos componentes da assistência farmacêutica, básico, estratégico e especializado, destinados à dispensação nas farmácias das unidades de saúde do SUS (Vieira, 2018). Também foram agregados a esse grupo, embora não façam parte da lista dos componentes mencionados, os medicamentos antineoplásicos. Essa decisão foi tomada dadas as suas características, em termos de preço e tempo de mercado, que são semelhantes às encontradas entre vários medicamentos que integram o componente especializado.

2) Judicialização: medicamentos adquiridos pelo MS em virtude de demanda judicial.

3) Ambulatório do MS: medicamentos comprados para atendimento aos servidores no ambulatório do edifício-sede do órgão. O ambulatório está sob a responsabilidade da Coordenação de Atenção à Saúde do Servidor (CAS).

4) Hospitais federais: medicamentos destinados aos hospitais federais do Rio de Janeiro, os quais são diretamente vinculados ao MS.

5) Saúde indígena: medicamentos adquiridos para dispensação nas unidades do Subsistema de Atenção à Saúde Indígena (Sasi), que estão sob a gestão dos Distritos Sanitários Especiais Indígenas (DSEI).

6) Kit calamidade: medicamentos destinados às Unidades da Federação (UFs) que enfrentem situação de calamidade em razão de desastres.

7) Outros: medicamentos que não puderam ser classificados nas categorias de destinação anteriores.

A classificação desses grupos foi feita considerando as informações incluídas nos campos de dados objeto e justificativa para dispensalinexigibilidade de licitaçâo do Siasg.

Para os medicamentos que compóem o grupo componentes da AF, foram incluídas informações constantes do sistema de classificação ATC/DDD, mantido por um centro colaborador da Organização Mundial da Saúde (OMS). O objetivo desse sistema é servir como ferramenta para o monitoramento e a pesquisa sobre o uso de medicamentos, possibilitando a comparação das estatísticas de consumo desses produtos. ${ }^{10}$

10. Ver: <https://bit.ly/3abUyE6>. Acesso em: 22 jul. 2020. 
No sistema de classificação ATC (Anatomical Therapeutic Chemical Classification System) com DDD (defined daily doses), os medicamentos são divididos em diferentes grupos de acordo com o órgão ou sistema sobre o qual atuam e suas propriedades químicas, farmacológicas e terapêuticas. ${ }^{11}$ Cada fármaco recebe um código e a DDD, quando estabelecida, é informada segundo a via de administraçáo dos medicamentos produzidos com o fármaco. ${ }^{12}$ Esse código foi utilizado para a identificação dos medicamentos adquiridos pelo MS, ${ }^{13}$ os quais foram agrupados para fins descritivos, considerando o segundo nível do sistema (subgrupos terapêuticos).

Para os medicamentos com DDD estabelecida, foi possível calcular a quantidade de DDDs adquiridas a partir das unidades físicas de cada produto comprado, constituindo assim a relação de medicamentos para a qual se realizou a decomposição do gasto. Com a informação do número de DDDs, calculou-se o preço por DDD de cada medicamento, dividindo-se o valor total da aquisição pelo número de DDDs. Esta é a variável preço utilizada na análise. Nos casos em que houve mais de uma compra do mesmo produto no ano, calculou-se o preço médio ponderado pela quantidade de DDDs.

Realizou-se correção monetária dos valores para preços de 2019 pela aplicação do Índice de Preços ao Consumidor Amplo (IPCA) médio, a fim de uniformizar o valor monetário da moeda e possibilitar a comparação dos valores entre os anos. Essa correção é importante porque o gasto real em medicamentos é afetado pela inflação geral da economia (Mousnad, Shafie e Ibrahim, 2014). Utilizou-se o IPCA na atualização monetária porque ele é o medidor de inflação oficial no Brasil, sendo utilizado como o índice de referência para o sistema de metas de inflação e a indexação de títulos públicos (BCB, 2016).

\subsection{Indutores investigados e análise estatística}

Foram analisados os indutores principais do gasto em medicamentos: preço, quantidade e resíduo, conforme proposto por Gerdtham et al. (1998):

$$
\mathrm{I}_{\mathrm{G}}=\mathrm{I}_{\mathrm{P}} \cdot \mathrm{I}_{\mathrm{Q}} \cdot \mathrm{I}_{\mathrm{R}}
$$

11. Ver: <http://bit.ly/389VM2E >. Acesso em: 22 jul. 2020.

12. Medicamento é o produto acabado, pronto para uso. Fármaco é a molécula ativa responsável pelo efeito do medicamento. 13. 0 Código BR do Catmat não pôde ser utilizado para identificação dos produtos porque um mesmo fármaco pode ter dois ou mais códigos BR. Exemplo: metformina 500 mg (BR0267690) e metformina 850 mg (BR0267691). 
Em que:

- $\mathrm{I}_{\mathrm{G}}=$ índice do gasto em medicamentos;

- $\mathrm{I}_{\mathrm{P}}=$ índice dos preços por tratamento/dia;

- $\mathrm{I}_{\mathrm{Q}}=$ índice das quantidades (tratamentos diários); e

- $\mathrm{I}_{\mathrm{R}}=$ índice dos resíduos.

A análise foi feita com o suporte do RStudio versão 1.3.1056 e do pacote estatístico IndexNumR (White, 2020a; 2020b). As funçóes utilizadas deste pacote foram:

- evaluateMatched: para verificar a sobreposição dos medicamentos entre os anos analisados;

- priceIndex e quantityIndex com uso do método de Fisher, tanto para a base fixa (2010) quanto para a estimativa período a período (índice encadeado): ${ }^{14}$ para cálculo dos índices de preço e de quantidade dos medicamentos que compóem uma lista compartilhada entre os pares de anos analisados;

- values: para calcular o valor total do gasto na amostra a cada ano; e

- valueDecomposition com o uso do método de Bennet ${ }^{15}$ para os indicadores de preço e quantidade: para obtenção da decomposição do gasto anual segundo essas duas variáveis.

O método de Fisher foi o escolhido para cálculo dos índices de preço e de quantidade pelas razões apresentadas na seção 2.2 deste texto. Adicionalmente, são vantagens desse método: i) implementação simples; ii) robustez na mudança de sinal; iii) reversão temporal (simetria): o índice de preço (quantidade) para o período-base em relação ao período de comparação deve ser igual ao recíproco do índice de preço (quantidade) para o período de comparação em relação ao período-base; e iv) proporcionalidade em relação aos preços e às quantidades (Boer e Rodrigues, 2019).

O índice do gasto foi calculado utilizando-se das duas metodologias, base fixa e período a período, e o índice do resíduo a partir dos índices de gasto, preço e quantidade, conforme a seguinte fórmula:

$$
I_{R}=\frac{I_{G}}{\left(I_{P} \cdot I_{P}\right)}
$$

14. Um índice encadeado é um índice-número no qual o valor de um dado período é relacionado ao valor de seu período imediatamente precedente. Ver: <https://bit.ly/3giqWGf>. Acesso em: 22 jul. 2020.

15. Trata-se da média aritmética dos indicadores de preço de Laspeyres e Paasche (Boer e Rodrigues, 2019).

24 


\section{RESULTADOS E DISCUSSÃO}

Uma síntese das informaçóes sobre as compras realizadas pelo MS entre 2010 e 2019 é apresentada na tabela 2 . Nesta tabela, as aquisiçôes ${ }^{16}$ foram classificadas por grupos de destinação dos produtos em componentes da AF (SUS), judicialização, ambulatório MS, hospitais federais, saúde indígena, kit calamidade e outros.

Destaca-se, inicialmente, a expressiva participação das aquisiçóes decorrentes da judicialização no total das aquisições realizadas. A participação mínima foi de $76,9 \%$, o que ocorreu nos últimos dois anos da série, e a participação máxima foi de 95,8\% em 2012. Na média, a judicialização foi responsável por 91,9\% das aquisiçóes do MS entre 2010 e 2019, totalizando 24.796 compras no período. O número de aquisiçóes oscilou na série analisada, mas parece haver uma tendência de sua redução nos últimos dez anos. Foram 3.305 compras em 2010 e 856 em 2019.

É interessante notar que o número de compras diminuiu, mas o gasto nessas aquisiçôes parece não acompanhar a mesma tendência. Pelo contrário, entre 2010 e 2018, essa despesa cresceu a cada ano, o que sugere a aquisição de medicamentos mais caros. Foram R \$203,8 milhóes despendidos em 2010 e R \$ 1,4 bilhão em 2018. Em 2019, o valor reduziu para R \$ 972,9 milhóes. Em todo o período, o gasto foi de $\mathrm{R} \$ 8,5$ bilhóes, equivalentes a 10,3\% do gasto direto em medicamentos do MS (R \$ 82,1 bilhôes em valores de 2019).

O custo administrativo da realização dessas aquisiçôes pode ser elevado, uma vez que elas demandam muito tempo das equipes do MS para a compra dos diferentes produtos de múltiplos fornecedores, estabelecimento de controles específicos para acompanhamento do cumprimento das decisôes judiciais e contratação de empresas para a logística, a fim de que os produtos cheguem às mãos dos impetrantes das ações em todo o país.

Menor impacto, tanto administrativo quanto financeiro, geraram as aquisiçóes de medicamentos para disponibilização no ambulatório do MS, atendimento aos DSEI (saúde indígena), aos hospitais federais e constituição dos kits calamidade. Em todo o período, foram 643 compras para essas destinaçóes $(2,4 \%)$, totalizando $\mathrm{R} \$ 190,9$ milhóes em valores de 2019. Também se observa mudança na decisão sobre a realização dessas

16. Neste texto, uma aquisição corresponde à compra de um item (medicamento). Uma licitação pode incluir vários itens, portanto, o termo aquisição empregado no texto não é sinônimo de número de licitações. Além disso, um mesmo item pode ser adquirido mais de uma vez no ano. Cada um desses eventos é considerado mais uma aquisição. 
compras no período. Elas foram realizadas pelo departamento de logística do MS para atendimento ao ambulatório e aos hospitais até 2012 e, em 2018, com o apoio do MS às situaçóes de calamidade pública nos estados e municípios, aquele departamento passou a adquirir medicamentos específicos para atendimento a essas situaçóes.

Quanto aos kits calamidade, foram identificadas aquisições apenas a partir de 2018, mas sua instituição se deu em 2012 com a finalidade de atender as UFs atingidas por desastres de origem natural associados a chuvas, ventos e granizo (Brasil, 2012). Como a classificação dos itens foi feita a partir de informaçóes registradas em campo aberto do Siasg, é possível que nos outros anos a aquisição desses itens não tenha sido registrada de forma separada. Uma vez que se trata de medicamentos do componente básico, que não constam entre os itens classificados no grupo componentes da $\mathrm{AF}$, é provável que as compras para essa destinação entre 2012 e 2017 estejam misturadas às realizadas para atendimento à saúde indígena. $\mathrm{O}$ gasto com esses itens não deve ser significativo.

O grupo de maior impacto financeiro é o dos medicamentos constantes das listas dos componentes da AF, que neste estudo inclui antineoplásicos na etapa descritiva das despesas. Em número de compras realizadas, o grupo é o segundo de maior importância, ficando atrás dos medicamentos judicializados, contudo, em termos de recursos, respondeu por R \$ 73,5 bilhóes (89,4\% do gasto total) entre 2010 e 2019 e, de longe, é o mais importante. Isso é esperado, uma vez que se trata da compra de medicamentos que estão sob a responsabilidade do MS para dispensação nas farmácias do SUS em todo o país. Por isso, sua relevância para a análise dos indutores do gasto. Além disso, para essa análise, é importante que haja uma lista fixa (compartilhada) de produtos adquiridos entre os anos. Isso ocorre para os medicamentos da lista dos componentes da AF, mas, dificilmente acontece para os itens da judicialização, onde há muita variabilidade de produtos entre os anos e, aparentemente, uma tendência no sentido da demanda por medicamentos novos. Assim, o foco da análise da indução do gasto foi dirigido para este primeiro grupo de destinação de medicamentos. 


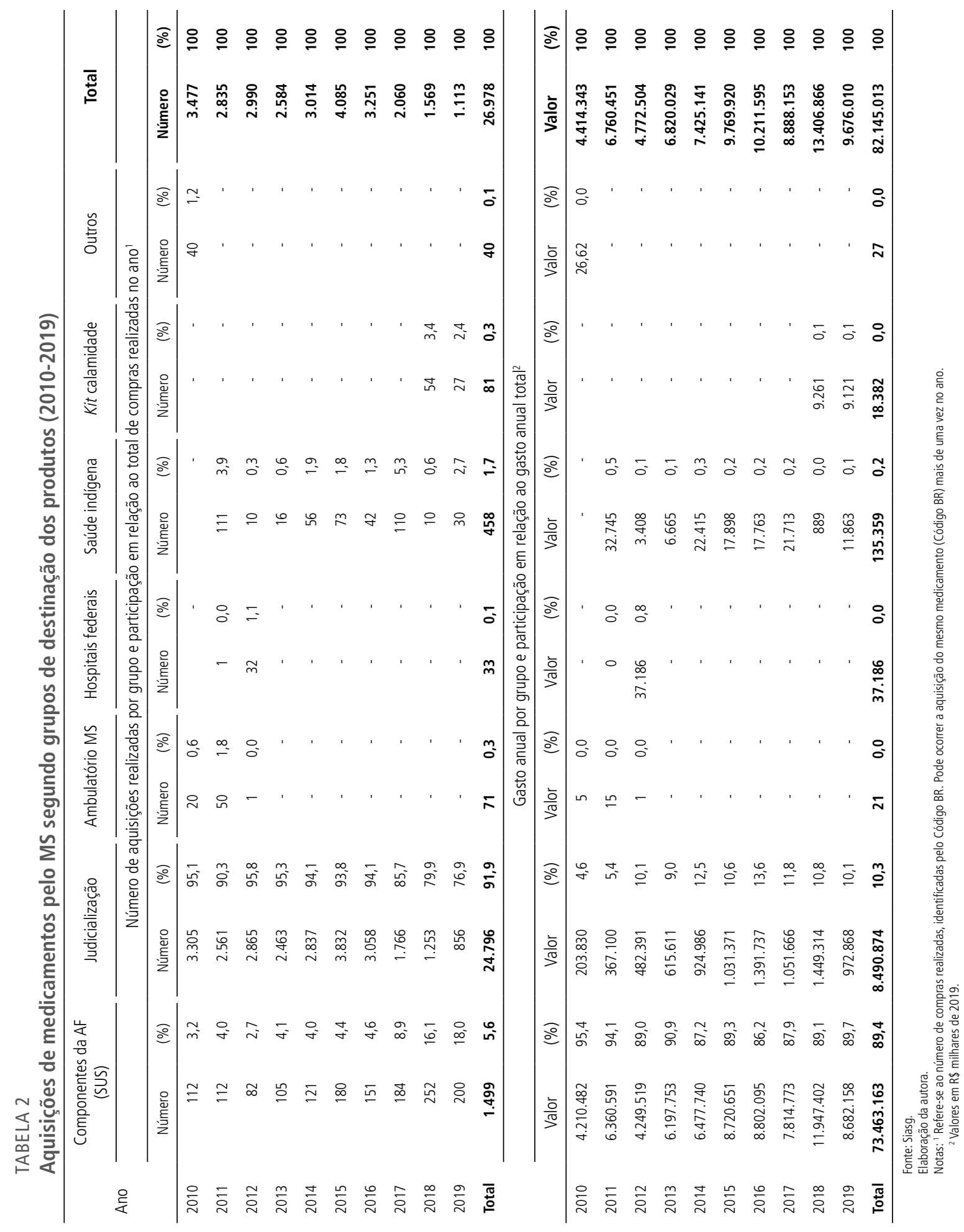


Após a definição do grupo de medicamentos para a análise, outra questão importante está relacionada à disponibilidade da DDD. Esta é estabelecida para cada fármaco, considerando a via de administração do produto final, ou seja, do medicamento. Para vários medicamentos, não é possível calcular uma dose diária média para tratamento de adultos, uma vez que a dose é altamente individualizada, ou seja, a quantidade de medicamento administrado varia de paciente a paciente. Este é o caso dos antineoplásicos, para os quais a dose varia substancialmente em funçáo dos diferentes tipos de tumores, da gravidade da doença e em decorrência do uso extensivo da combinação de vários medicamentos no tratamento. ${ }^{17}$

Para a análise dos indutores do gasto em medicamentos, recomenda-se a não utilização das quantidades físicas dos produtos, mas sim da quantidade de DDDs, que é uma aproximação ao número de tratamentos diários disponibilizados com cada medicamento (Gerdtham et al., 1998). Isso faz diferença para os medicamentos porque um único fármaco, utilizado para tratar o mesmo problema de saúde, pode ser produzido em diferentes formas farmacêuticas, concentrações e apresentaçôes.

Por exemplo, o fármaco carbamazepina, que é anticonvulsivante, tem por formas farmacêuticas comprimidos e suspensão oral; por concentraçóes, $200 \mathrm{mg}$, $400 \mathrm{mg}$ e 20 $\mathrm{mg} / \mathrm{ml}$; e por apresentação, caixa com vinte ou trinta comprimidos, frasco com $100 \mathrm{ml}$, entre outras. Se a análise for feita pelas quantidades físicas de cada produto, cada combinação do fármaco carbamazepina, segundo a forma, a concentração e a apresentação, será contabilizada como um medicamento distinto. Embora o governo federal mantenha o Catmat e tenha padronizado cada medicamento, essa padronização reúne sob cada código, chamado de Código BR, informação sobre o fármaco, concentração e forma farmacêutica (Brasil, 2017). Isso significa que cada código diz respeito à combinação dessas três variáveis e, portanto, há códigos diferentes para o mesmo fármaco.

Diferentemente, quando se utiliza a DDD da carbamazepina, que é de $1 \mathrm{~g}$ por via oral, identificada por seu código ATC, as quantidades físicas de cada medicamento à base desse fármaco podem ser convertidas em números de DDD e fazem mais sentido para a análise dos indutores do gasto, dada a importância do resíduo, que envolve mudanças nas despesas relativas às escolhas terapêuticas feitas entre os períodos comparados. Por essa razão, verificou-se se há DDD estabelecida pela OMS para cada medicamento constante

17. Ver: <https://bit.ly/3fxPdYx>. Consultar, por exemplo, o código ATC "L" que corresponde ao grupo dos agentes antineoplásicos e imunomoduladores. 
da lista dos componentes da AF. Das 1.499 aquisiçóes de medicamentos desse grupo realizadas entre 2010 e 2019, 1.005 possuem DDD estabelecida (67\%).

Como mencionado na seção 3, sobre os métodos deste estudo, os antineoplásicos não integram a lista dos componentes da AF. Para uma análise mais descritiva, eles foram agregados aos itens dos componentes, porque o MS centraliza a compra, se não de toda a quantidade necessária desses medicamentos para o SUS, de pelo menos parte expressiva. Isso ocorre porque os itens têm elevado impacto sobre o gasto. Entretanto, eles integram o subgrupo de medicamentos para os quais não há DDD estabelecida. Nesse subgrupo (medicamentos sem DDD estabelecida), os maiores gastos no período foram em vacinas ( $\mathrm{R} \$ 13,0$ bilhôes), anti-hemorrágicos ( $\mathrm{R}$ \$ 8,8 bilhóes), antineoplásicos ( $\mathrm{R}$ \$ 4,8 bilhôes) e em soros e imunoglobulinas ( $\mathrm{R}$ \$ 2,8 bilhôes). Ao todo, foram destinados R \$ 32,1 bilhóes entre 2010 e 2019. Quanto ao outro subgrupo, dos medicamentos que possuem $\mathrm{DDD}$, do gasto total de $\mathrm{R} \$ 73,5$ bilhóes com o grupo componentes da $\mathrm{AF}$, $\mathrm{R} \$ 41,4$ bilhóes $(56,4 \%)$ foram alocados à sua compra. O detalhamento das aquisiçóes, do número de fármacos e das despesas deste subgrupo é apresentado na tabela 3.

TABELA 3

Medicamentos adquiridos da lista dos componentes da AF (SUS) com DDD estabelecida para os seus fármacos pela OMS (2010-2019)

\begin{tabular}{lccc}
\hline Anos & Número de aquisições & & $\begin{array}{c}\text { Valor }^{3} \\
\text { (R\$) }\end{array}$ \\
\hline 2010 & 67 & Número de fármacos $^{2}$ & 3.574 .910 \\
2011 & 72 & 39 & 4.817 .134 \\
2012 & 69 & 40 & 3.611 .436 \\
2013 & 81 & 38 & 4.678 .757 \\
2014 & 88 & 45 & 4.338 .574 \\
2015 & 104 & 54 & 5.147 .124 \\
2016 & 90 & 64 & 3.612 .425 \\
2017 & 127 & 59 & 3.454 .369 \\
2018 & 180 & 62 & 4.674 .269 \\
2019 & 127 & 74 & 3.522 .248 \\
Total & 1.005 & 72 & $\mathbf{4 1 . 4 3 1 . 2 4 6}$ \\
\hline & Fonte: Siasg. & & \\
& Elaboração da autora. & &
\end{tabular}

Nota-se, na tabela 3, o aumento do número de aquisiçôes e de fármacos ao longo da década. O gasto oscilou entre os anos, tendo alcançado o maior patamar em 2015, quando foi de R \$ 5,1 bilhôes. Contudo, reduziu-se para R \$ 3,5 bilhôes em 2019. 
O aumento do número de fármacos e, consequentemente, das aquisições está relacionado à centralização da aquisição de medicamentos do componente especializado no MS e à ampliação da incorporação de medicamentos que acabaram ficando sob a responsabilidade do órgão (Vieira, 2018; 2019).

Pactuaçóes entre o MS e as secretarias estaduais de saúde têm ampliado a participaçáo do governo federal na compra e distribuição de medicamentos, o que é mais vantajoso do ponto de vista econômico, visto que parcela expressiva desses produtos tem fornecedor exclusivo, seu preço é elevado e as aquisiçóes centralizadas podem gerar economia de escala (Brasil, 2014). Entre 2007 e 2016, registraram-se aumento do gasto do MS em medicamentos em situação de exclusividade de fornecimento no Brasil e que estavam sob a responsabilidade de compra do MS (de $\mathrm{R} \$ 1,1$ milhão para $\mathrm{R} \$ 2,3$ bilhóes a preços constantes), e redução dos preços desses produtos após a incorporação ou centralização da aquisição no governo federal (Chaves et al., 2018). Quanto à incorporação, os medicamentos têm sido a tecnologia mais demandada e avaliada pela Comissão Nacional de Incorporação de Tecnologias (Conitec) no SUS, bem como a que mais tem decisão favorável à sua inclusão no sistema pelo MS (Caetano et al., 2017).

Se de um lado, houve ampliação dos fármacos e das aquisiçôes, sendo esse movimento consistente com as decisóes na área de assistência farmacêutica em âmbito nacional na última década, por outro, chama a atenção a variação do gasto anual com aumento e redução importantes entre alguns anos. A despesa em 2019 ( $\mathrm{R}$ \$ 3,5 bilhôes) foi ligeiramente menor que a realizada em 2010 (R \$ 3,6 bilhões). Tal oscilação demanda análise de seus indutores, como a proposta neste estudo. Mas antes de avançar nessa questáo, é importante descrever os medicamentos objeto desta análise. Na tabela 4, apresenta-se o gasto do MS nos medicamentos que têm DDD estabelecida, segundo os subgrupos terapêuticos aos quais pertencem.

Verifica-se, com base nos valores apresentados na tabela 4, que os subgrupos de maior impacto sobre o gasto em 2010 foram os de imunossupressores, imunoestimulantes, antimicóticos e antivirais para uso sistêmico. $\mathrm{Na}$ comparação da despesa em 2019 em relação à executada em 2010, há significativa redução para os três primeiros subgrupos, $-64 \%,-89 \%$ e $-77 \%$, respectivamente, e aumento do gasto em antivirais de uso sistêmico (357\%). A despesa realizada com esse último subgrupo havia sido maior em 2015, mas teve queda nos anos subsequentes, com alguma elevação do patamar em 2018, para daí experimentar nova redução em 2019. 
Um estudo realizado sobre os indutores do gasto federal em imunossupressores, o que inclui não apenas as aquisiçóes feitas pelo MS, mas também todas aquelas realizadas pelos demais órgãos dessa esfera de governo, que têm ampla rede de hospitais de ensino e pesquisa, mostrou que o principal indutor do aumento do gasto entre 2010 e 2015 foi a quantidade de medicamentos adquirida. Este estudo também revelou reduçáo de 37\% nos preços dos produtos entre os dois anos (Alves et al., 2018). Não se identificaram outras investigaçóes dessa natureza para esse subgrupo, abrangendo período mais recente, ou para os outros subgrupos terapêuticos em qualquer período. Os imunossupressores constituem uma classe de medicamentos extremamente importante pelo impacto que geram para os gastos em medicamentos dos países, considerando os altos preços dos produtos, especialmente dos mais novos, os quais impossibilitam em muitos casos o acesso da população a eles. Mesmo em países de alta renda, como os Estados Unidos, o debate se coloca sobre a cobertura desses medicamentos pelos programas públicos, Medicaid e Medicare, e sobre a capacidade de pagamento da população (Grubbs, 2019).

Quanto aos medicamentos usados no tratamento da diabetes, houve aumento modesto entre 2010 e 2019 (9\%), mas o gasto em 2018 foi cinco vezes maior ao realizado em 2019. Também chama a atenção a não realização de despesas nesses medicamentos em 2015 e 2016, uma vez que a compra de insulinas para dispensação no SUS está sob a responsabilidade do MS. ${ }^{18}$ Isso pode ter gerado indisponibilidade desses medicamentos nas farmácias das unidades de saúde. Contudo, o problema pode ter sido amenizado pela dispensação gratuita desses produtos nas farmácias privadas, credenciadas ao Programa Farmácia Popular do Brasil, que teve crescimento expressivo do número de usuários entre 2013 e 2018 (Almeida e Vieira, 2020). As causas das inconstâncias na compra de insulinas pelo MS precisam ser investigadas. Os antidiabéticos estáo entre os medicamentos mais consumidos em todo o mundo. Em países da OCDE, o consumo de DDDs por mil habitantes aumentou em média 5\% ao ano (a.a.) entre 2005 e 2013 (Belloni, Morgan e Paris, 2016). Na Finlândia, os principais indutores do crescimento do gasto nesses medicamentos foram o aumento do volume e a mudança da prática clínica para medicamentos novos e mais caros (Soppi et al., 2018).

18. Entre 2010 e 2019, as insulinas adquiridas foram a NPH e a regular. Embora a incorporação da insulina análoga de ação prolongada tenha sido decidida pelo MS em março de 2019, não houve aquisição do medicamento nesse ano. Ver relatório da Conitec em: <https://bit.ly/32vvKDF>. Acesso em: 8 ago. 2020. 


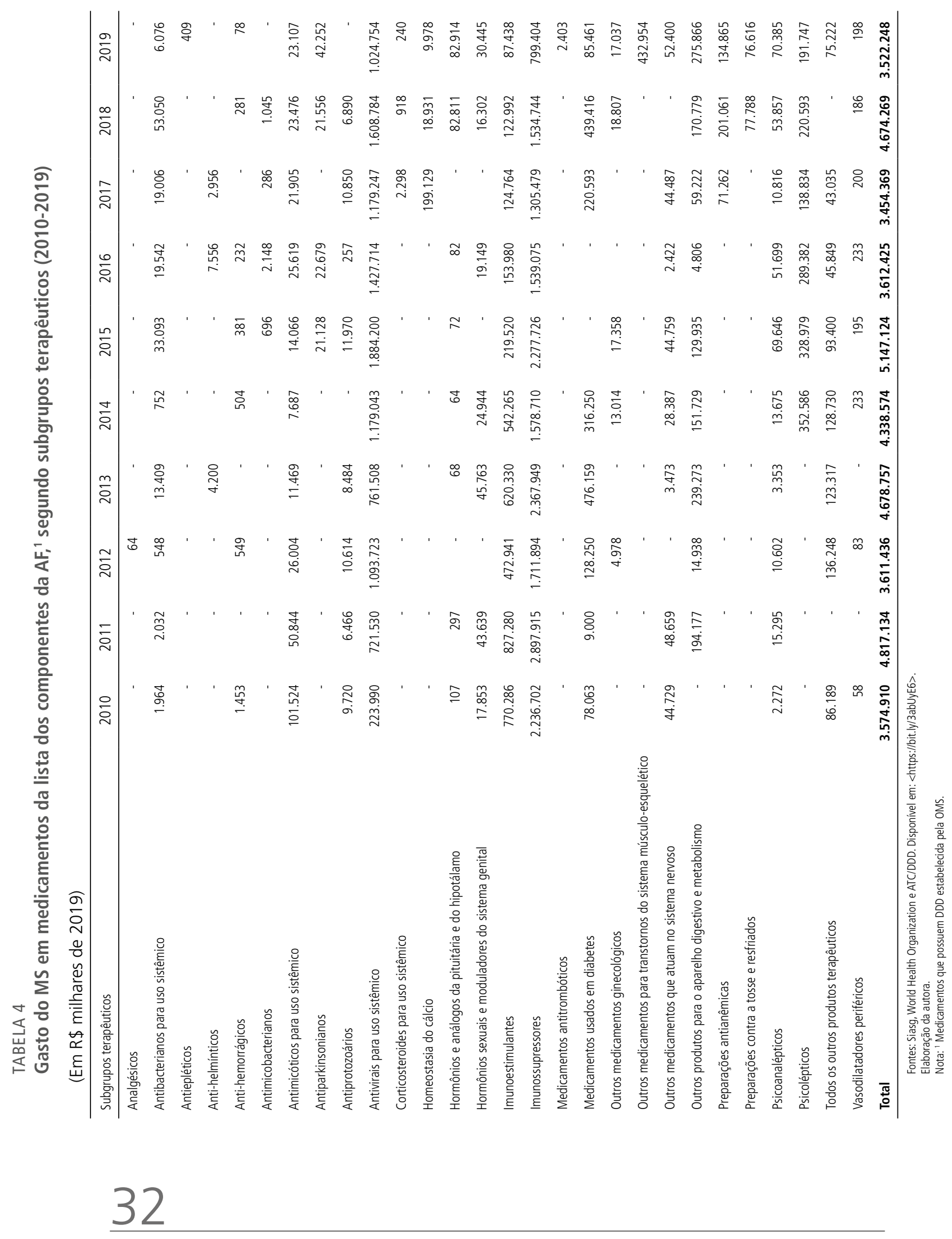


A seguir, na tabela 5, apresentam-se os resultados da análise dos indutores do gasto em medicamentos, considerando dois métodos de comparaçáo, base fixa (2010) e período a período. No primeiro caso, a participaçáo de cada indutor foi calculada em comparação a 2010 e, no segundo caso, foi calculado entre o ano corrente e o ano anterior. Chama-se a atençáo para o fato de que, na análise dos preços e das quantidades, uma lista compartilhada de medicamentos é comparada entre os dois períodos. Isso significa que no método base fixa, os preços e as quantidades dos mesmos itens são comparados a cada ano em relação a 2010. No método periodo a periodo, uma lista coincidente de itens é comparada ano a ano.

TABELA 5

Indutores do gasto do MS em medicamentos ${ }^{1}$ (2010-2019)

(Em \%)

\begin{tabular}{|c|c|c|c|c|}
\hline \multicolumn{5}{|c|}{$\begin{array}{c}\text { Em relação a } 2010 \\
\text { (Base fixa) }\end{array}$} \\
\hline Anos & Gasto & Preço & Quantidade & Resíduo \\
\hline 2010 & - & - & - & - \\
\hline 2011 & 34,7 & $-23,0$ & 52,0 & 15,1 \\
\hline 2012 & 1,0 & $-36,0$ & 87,0 & $-15,6$ \\
\hline 2013 & 30,9 & $-46,0$ & 128,0 & 6,3 \\
\hline 2014 & 21,4 & $-51,0$ & 200,0 & $-17,4$ \\
\hline 2015 & 44,0 & $-51,0$ & 142,0 & 21,4 \\
\hline 2016 & 1,0 & $-62,0$ & 143,0 & 9,4 \\
\hline 2017 & $-3,4$ & $-69,0$ & 203,0 & 2,9 \\
\hline 2018 & 30,8 & $-69,0$ & 232,0 & 27,0 \\
\hline 2019 & $-1,5$ & $-55,0$ & 77,0 & 23,7 \\
\hline \multicolumn{5}{|c|}{$\begin{array}{l}\text { Em relação ao ano anterior } \\
\text { (Período a período) }\end{array}$} \\
\hline Ano & Gasto & Preço & Quantidade & Resíduo \\
\hline 2010 & - & - & - & - \\
\hline 2011 & 34,7 & $-23,0$ & 52,0 & 15,1 \\
\hline 2012 & $-25,0$ & $-16,0$ & 5,0 & $-15,0$ \\
\hline 2013 & 29,6 & $-17,0$ & 35,0 & 15,6 \\
\hline 2014 & $-7,3$ & $-6,0$ & $-6,0$ & 4,9 \\
\hline 2015 & 18,6 & $-5,0$ & $-9,0$ & 37,2 \\
\hline 2016 & $-29,8$ & $-21,0$ & $-13,0$ & 2,1 \\
\hline 2017 & $-4,4$ & $-20,0$ & 15,0 & 3,9 \\
\hline 2018 & 35,3 & $-7,0$ & 20,0 & 21,2 \\
\hline 2019 & $-24,6$ & $-6,0$ & $-17,0$ & $-3,4$ \\
\hline
\end{tabular}


Na prática, tem-se que a lista de medicamentos comparada pelo método base fixa é mais restrita do que a considerada no método periodo a periodo. Isso ocorre porque ao longo dos anos houve incorporaçáo de medicamentos pelo MS e centralizaçáo da compra de itens antes adquiridos pelas secretarias estaduais de saúde. Essa constatação é relevante, porque a lista de itens comparados pode ser bem diferente quanto ao perfil dos medicamentos considerando os dois métodos. A incorporação de novos medicamentos que ficam sob a responsabilidade de aquisição do MS envolve geralmente itens com fornecedor único e a decisão da centralização ocorre por razóes de mercado, frequentemente porque os produtos têm preço elevado ou há poucos ou apenas um fornecedor. Assim, no primeiro método, pode estar sendo comparada uma lista de produtos que ganha mais concorrentes no mercado (incluindo medicamentos genéricos e similares) com o passar dos anos e, no segundo método, uma lista mais restritiva em termos de concorrentes. Isso ajuda a explicar as diferenças de redução de preços entre os dois métodos de comparação, que é mais pronunciada para o primeiro.

Nota-se, na tabela 5, que, em relação a 2010, há aumento significativo da quantidade adquirida até 2018, que também aumenta em 2019, mas em percentual menor. Nesse último ano, a redução observada de $1,5 \%$ do gasto foi induzida pela queda dos preços dos medicamentos (-55\%). Houve aumento da quantidade (77\%) e do resíduo $(23,7 \%)$ que, neste último caso, indica realização de despesa em medicamentos que não foram comprados em 2010 e/ou aumento do preço médio por DDD, considerando os produtos disponíveis nos dois anos, em virtude de mudança no padrão terapêutico. Ou seja, o impacto da redução de preços foi maior na induçáo do gasto que o do aumento da quantidade comprada em 2019 para itens também adquiridos em 2010 e o do aumento do gasto com outros medicamentos e/ou devido à alteração no padráo terapêutico.

$\mathrm{Na}$ comparação período a período, os preços reduzem em todos os anos, entretanto, a magnitude dessa redução não é suficiente para induzir o gasto em alguns deles, dado o aumento da quantidade e/ou do resíduo. Em 2015, por exemplo, em relação a 2014, o gasto teve aumento de $18,6 \%$, sendo que houve redução de $5 \%$ nos preços, $9 \%$ nas quantidades e ampliação do resíduo em $37,2 \%$. Ou seja, a compra de itens não adquiridos em 2014 induziu o aumento do gasto, o que geralmente envolve a incorporação de medicamentos, a centralização da compra no MS e eventual aquisição de um produto que já consta da Relação Nacional de Medicamentos Essenciais (Rename) e está sob a responsabilidade do MS, mas náo foi comprado em 2014. Também pode ter ocorrido alteração do padrão terapêutico para os itens disponíveis nos dois anos. Ressalta-se aqui a possibilidade de maior contribuição da incorporação de medicamentos novos, que tem 
sido apontada como um importante indutor para o aumento do gasto em medicamentos dos países em todo o mundo (Karampli et al., 2014; Belloni, Morgan e Paris, 2016).

Ainda na tabela 5, destacam-se mais dois anos na comparação período a período: 2016 e 2019. Em 2016, o Brasil enfrentou grave crise política e econômica, com impactos para o financiamento federal do SUS (Ipea, 2019). O gasto em medicamentos teve queda de $29,8 \%$ em relação ao realizado em 2015 , havendo redução do preço $(-21 \%)$ e da quantidade $(-13 \%)$. O crescimento do resíduo foi modesto $(2,1 \%)$. A crise econômica e as medidas de austeridade implementadas sob o argumento da necessidade de realizar o ajuste das contas públicas podem ter papel central na situação observada naquele ano (Santos e Vieira, 2018). Em 2019, várias notícias em jornais de grande circulação informaram da falta de medicamentos que estáo sob a responsabilidade de aquisição do MS em vários estados e o tema foi debatido em reunião do Conselho Nacional de Saúde (CNS). ${ }^{19} \mathrm{Na}$ tabela 5, observa-se que naquele ano em relação a 2018, o gasto diminuiu $24,7 \%$ havendo queda de $17 \%$ na quantidade adquirida, o que é uma evidência a favor da hipótese de reduçáo da disponibilidade de alguns medicamentos financiados pelo MS no SUS.

A evolução dos indutores do gasto para o método base fixa é apresentada no gráfico 1 . Neste gráfico, fica claro que, para os mesmos itens adquiridos em 2010 e em 2018, a quantidade aumentou significativamente nesse último ano (232\%). Na comparação entre 2010 e 2019, o aumento foi de $77 \%$. Se a quantidade adquirida em 2018 era suficiente apenas para atender a demanda daquele ano, entáo, a compra realizada em 2019 pode ter sido feita em volume aquém do necessário.

19. Ver CNS (2019). 
GRÁFICO 1

Variação dos indutores do gasto do MS em medicamentos a cada ano em comparação a 2010 (2011-2019)

(Em \%)

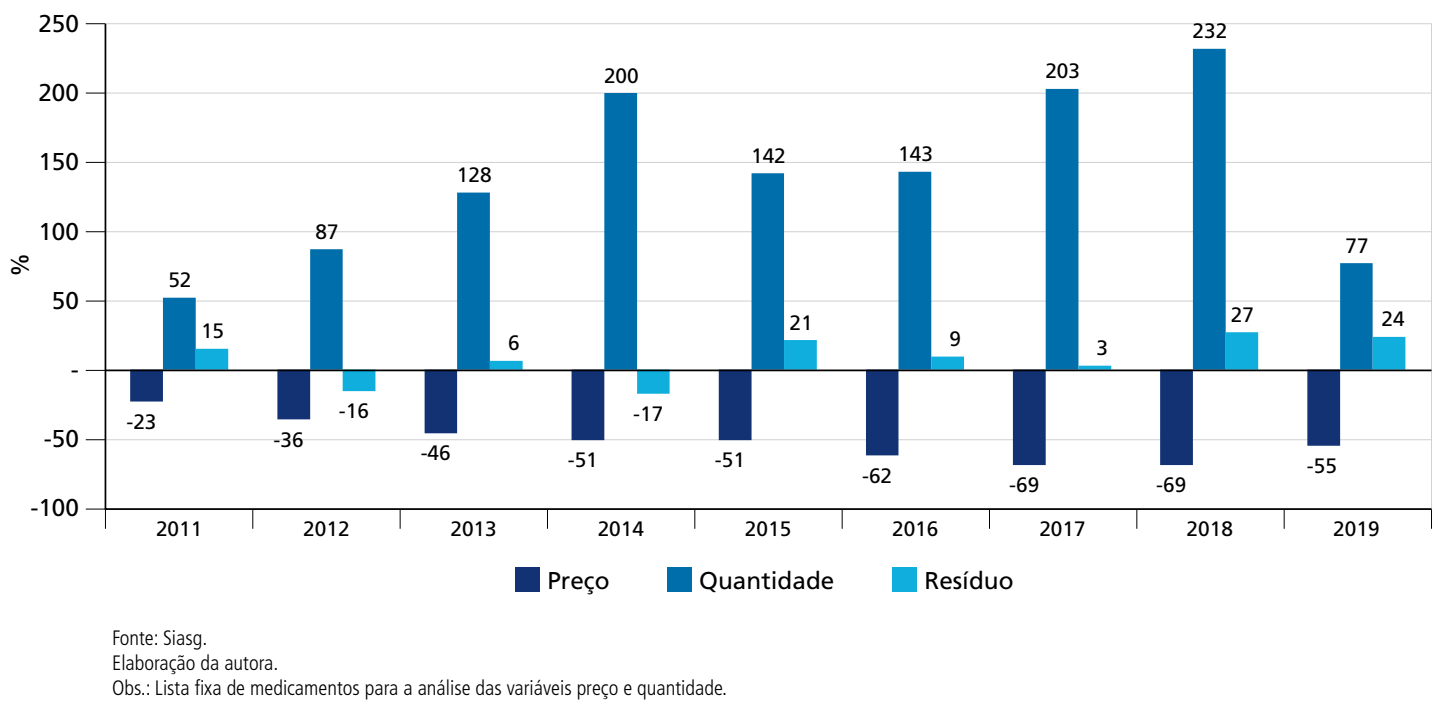

Esse comportamento é coerente com o observado em estudos internacionais, que mostram que os principais indutores do crescimento do gasto são o aumento da quantidade de produtos constantes da lista dos países e a incorporaçáo de medicamentos novos, que geralmente são mais caros. Os preços dos medicamentos disponibilizados tendem a reduzir ao longo dos anos e seu impacto é negativo sobre o gasto (Petrou, 2014; Thai et al., 2016; Belloni, Morgan e Paris, 2016).

Na tabela 6, apresentam-se o gasto anual, em uma lista compartilhada de medicamentos entre os anos analisados, o número de fármacos adquiridos no ano e o número de fármacos compartilhados entre os anos. No método base fixa, observa-se significativa redução do número de fármacos adquiridos nos anos analisados em relação a 2010, o que se reflete no gasto. O número de fármacos compartilhados entre 2010 e 2011 foi de 29 , com gasto de $\mathrm{R} \$ 3,98$ bilhôes, tendo este número reduzido para quatro na comparaçáo entre 2010 e 2019, com gasto de R \$ 149,21 milhóes. Na comparação período a período, o número de fármacos compartilhados cresceu e o gasto oscilou entre os anos. Esses achados revelam que houve modificação importante na lista de produtos adquiridos pelo MS desde 2010 para os medicamentos com DDD estabelecida, integrantes dos componentes básico, estratégico e especializado da $\mathrm{AF}$, sendo que vários fármacos deixaram de ser comprados, enquanto outros passaram a compor a lista de aquisiçáo. Para entender melhor esses movimentos, seria preciso analisar a lista de medicamentos 
adquirida a cada ano, pois tais mudanças refletem as pactuações envolvendo as responsabilidades pela compra dos medicamentos (descentralização para estados e municípios e centralização no MS), desincorporação e incorporação de medicamentos ao SUS, além de periodicidade maior que um ano da aquisição de medicamentos que já estão sob a responsabilidade do MS. Investigaçáo dessa natureza poderá ser realizada em outro estudo.

TABELA 6

Gasto do MS para uma lista compartilhada de medicamentos ${ }^{1}$ em dois períodos segundo os métodos de comparação base fixa e período a período (2010-2019)

\begin{tabular}{|c|c|c|c|c|c|c|}
\hline \multicolumn{7}{|c|}{$\begin{array}{c}\text { Em relação a } 2010 \\
\text { (Base fixa) }\end{array}$} \\
\hline \multirow[b]{2}{*}{ Anos } & \multicolumn{3}{|c|}{ Gasto $^{2}$} & \multicolumn{3}{|c|}{ Fármacos } \\
\hline & Anual (A) & $\begin{array}{l}\text { Em fármacos também } \\
\text { adquiridos em } 2010 \\
\text { (B) }\end{array}$ & $\begin{array}{c}\text { Participação (\%) } \\
(\mathrm{C})=(\mathrm{B}) /(\mathrm{A})\end{array}$ & $\begin{array}{l}\text { Adquiridos no ano } \\
\text { (D) }\end{array}$ & $\begin{array}{l}\text { Também adquiridos } \\
\text { em } 2010 \\
\text { (E) }\end{array}$ & $\begin{array}{c}\text { Participação (\%) } \\
(\mathrm{F})=(\mathrm{E}) /(\mathrm{D})\end{array}$ \\
\hline 2010 & - & - & - & - & - & - \\
\hline 2011 & 4.817 .134 & 3.979 .477 & 82,6 & 40 & 29 & 72,5 \\
\hline 2012 & 3.611 .436 & 2.435 .856 & 67,4 & 38 & 19 & 50,0 \\
\hline 2013 & 4.678 .757 & 2.474 .598 & 52,9 & 45 & 18 & 40,0 \\
\hline 2014 & 4.338 .574 & 1.693 .206 & 39,0 & 54 & 14 & 25,9 \\
\hline 2015 & 5.147 .124 & 1.359 .001 & 26,4 & 64 & 11 & 17,2 \\
\hline 2016 & 3.612 .425 & 974.556 & 27,0 & 59 & 9 & 15,3 \\
\hline 2017 & 3.454 .369 & 992.884 & 28,7 & 62 & 9 & 14,5 \\
\hline 2018 & 4.674 .269 & 872.365 & 18,7 & 74 & 6 & 8,1 \\
\hline 2019 & 3.522 .248 & 149.208 & 4,2 & 72 & 4 & 5,6 \\
\hline \multicolumn{7}{|c|}{$\begin{array}{l}\text { Em relação ao ano anterior } \\
\text { (Período a período) }\end{array}$} \\
\hline \multirow[b]{2}{*}{ Anos } & \multicolumn{3}{|c|}{ Gasto $^{2}$} & \multicolumn{3}{|c|}{ Fármacos } \\
\hline & Anual (A) & $\begin{array}{l}\text { Em fármacos também } \\
\text { adquiridos no ano anterior } \\
\text { (F) }\end{array}$ & $\begin{array}{l}\text { Participação (\%) } \\
(\mathrm{G})=(\mathrm{F}) /(\mathrm{A})\end{array}$ & $\begin{array}{l}\text { Adquiridos no ano } \\
\text { (D) }\end{array}$ & $\begin{array}{l}\text { Também adquiridos } \\
\text { no ano anterior } \\
\text { (H) }\end{array}$ & $\begin{array}{c}\text { Participação (\%) } \\
(\mathrm{I})=(\mathrm{H}) /(\mathrm{D})\end{array}$ \\
\hline 2010 & - & - & - & - & - & - \\
\hline 2011 & 4.817 .134 & 3.979 .477 & 82,6 & 40 & 29 & 72,5 \\
\hline 2012 & 3.611 .436 & 2.965 .407 & 82,1 & 38 & 25 & 65,8 \\
\hline 2013 & 4.678 .757 & 3.386 .083 & 72,4 & 45 & 25 & 55,6 \\
\hline 2014 & 4.338 .574 & 3.124 .330 & 72,0 & 54 & 34 & 63,0 \\
\hline 2015 & 5.147 .124 & 2.739 .583 & 53,2 & 64 & 41 & 64,1 \\
\hline 2016 & 3.612 .425 & 3.063 .813 & 84,8 & 59 & 46 & 78,0 \\
\hline 2017 & 3.454 .369 & 2.418 .940 & 70,0 & 62 & 40 & 64,5 \\
\hline 2018 & 4.674 .269 & 3.037 .864 & 65,0 & 74 & 42 & 56,8 \\
\hline 2019 & 3.522 .248 & 2.587 .590 & 73,5 & 72 & 51 & 70,8 \\
\hline \multicolumn{7}{|c|}{$\begin{array}{l}\text { Fonte: Siasg. } \\
\text { Elaboração da autora. } \\
\text { Notas: 'Medicamentos incluídos na lista dos componentes da AF (SUS) e que possuem DDD estabelecida pela OMS. } \\
{ }^{2} \text { 'Valores em R\$ milhares de } 2019 .\end{array}$} \\
\hline
\end{tabular}


$\mathrm{Na}$ tabela 7, apresenta-se o gasto anual, a parcela que foi comprometida com a compra de itens adquiridos no ano imediatamente anterior e com outros medicamentos período a período. Nela os valores alocados e a participação da aquisição de lista compartilhada de medicamentos entre os anos e de outros medicamentos no gasto total ficam mais evidentes. Em 2015, ano em que o resíduo induziu mais significativamente o aumento do gasto em medicamentos, observa-se que o montante alocado com a aquisição de outros medicamentos foi de R \$ 2,4 bilhóes, com participação de 46,5\% no gasto do ano. Aqui é importante esclarecer que parte do efeito do resíduo pode se dar para a lista compartilhada de medicamentos, pois envolve eventuais mudanças no padrão de tratamento envolvendo os produtos disponíveis. Mas é muito provável que a maior parcela desse efeito decorra da aquisição de outros medicamentos, não comprados no ano anterior.

\section{TABELA 7}

Gasto em medicamentos: ${ }^{1}$ anual, em produtos adquiridos no ano anterior e em outros produtos (2010-2019)

\begin{tabular}{|c|c|c|c|c|c|}
\hline \multirow[b]{2}{*}{ Anos } & \multirow[b]{2}{*}{ Gasto anual } & \multicolumn{2}{|c|}{ Medicamentos adquiridos no ano anterior ${ }^{2}$} & \multicolumn{2}{|c|}{ Outros medicamentos ${ }^{3}$} \\
\hline & & Valor & $\begin{array}{l}\text { Participação no gasto anual } \\
\qquad(\%)\end{array}$ & Valor & $\begin{array}{c}\text { Participação no gasto anual } \\
\qquad(\%)\end{array}$ \\
\hline 2010 & 3.574 .910 & - & - & - & - \\
\hline 2011 & 4.817 .134 & 3.979 .477 & 82,6 & 837.657 & 17,4 \\
\hline 2012 & 3.611 .436 & 2.965 .407 & 82,1 & 646.029 & 17,9 \\
\hline 2013 & 4.678 .757 & 3.386 .083 & 72,4 & 1.292 .673 & 27,6 \\
\hline 2014 & 4.338 .574 & 3.124 .330 & 72,0 & 1.214 .244 & 28,0 \\
\hline 2015 & 5.147 .124 & 2.739 .583 & 53,2 & 2.407 .540 & 46,8 \\
\hline 2016 & 3.612 .425 & 3.063 .813 & 84,8 & 548.612 & 15,2 \\
\hline 2017 & 3.454 .369 & 2.418 .940 & 70,0 & 1.035 .429 & 30,0 \\
\hline 2018 & 4.674 .269 & 3.037 .864 & 65,0 & 1.636 .405 & 35,0 \\
\hline 2019 & 3.522 .248 & 2.587 .590 & 73,5 & 934.658 & 26,5 \\
\hline
\end{tabular}

Nota-se aumento do gasto em outros medicamentos entre 2013 e 2015, e queda em 2016 e 2019. Nos primeiros anos, o crescimento pode ser atribuído à criação da Conitec, o que contribuiu para a ampliação da incorporaçáo de medicamentos. A comissão foi criada em 2011 para assessorar o MS nas decisóes sobre a incorporação, a exclusão ou a alteração de medicamentos, produtos para a saúde e procedimentos, além da elaboração ou alteração de protocolo clínico ou de diretriz terapêutica. 
Uma vez decidida a incorporação do medicamento, o SUS tem até 180 dias para disponibilizar o medicamento nas suas farmácias (Brasil, 2011). Nos anos que se seguiram ao de instituição da comissão, cresceu o número de medicamentos incorporados ao sistema (Caetano et al., 2017; Vieira, 2019). Outro fator importante para o crescimento do gasto em outros medicamentos nesse período foi a centralizaçáo da aquisiçáo no MS de medicamentos incorporados ao SUS (Brasil, 2014), como mencionado antes.

No tocante à incorporação de medicamentos, é preciso considerar a participação de produtos recém-lançados no mercado e protegidos por patentes no total de itens incorporados, por causa de seu impacto sobre as despesas. Estudo realizado com o objetivo de investigar o nível da proteçâo patentária de medicamentos de 22 países da OCDE e seus gastos em medicamentos entre 1970 e 2009, encontrou forte associação positiva entre as duas variáveis. Quanto maior o nível de proteção patentária, mais elevado foi o gasto, e esse efeito foi mais pronunciado em países com menor mercado farmacêutico (Jung e Kwon, 2018).

Quanto à redução do gasto em outros medicamentos em 2016 e 2019 em relação ao ano anterior (2015 e 2018, respectivamente), o que também ocorre para o gasto anual, uma característica comum dos dois anos é que houve mudança de governo na esfera federal e isso pode ter resultado em alteraçóes administrativas com impactos na capacidade de operacionalização dos processos de aquisição do órgão. E mesmo mudanças administrativas prévias podem ter contribuído para essa reduçáo. Em 2018, por exemplo, o MS deixou de fazer aquisições de medicamentos para períodos mais longos. Com a transição de governo em 2019, a falta de estoque de medicamentos para os primeiros meses do ano comprometeu a disponibilidade dos produtos no SUS. ${ }^{20}$ Ademais, a restrição orçamentária pode ter contribuído para que o MS desacelerasse a incorporação de novos medicamentos e a centralização de compras de produtos incorporados ao sistema. ${ }^{21}$

Uma questão a ser investigada é a da substituição de medicamentos a fim de esclarecer melhor os movimentos de aumento e de reduçáo do gasto em medicamentos existentes nos dois períodos e em outros produtos. Uma análise sobre as avaliaçôes feitas pela Conitec entre 2012 e junho de 2016 mostra que as solicitaçóes de desincorporação

20. Ver matéria Crise de abastecimento em: <https://bit.ly/3ieGD2G>. Acesso em: 8 ago. 2020.

21. 0 CNS se manifestou sobre a redução do orçamento para medicamentos em audiência pública realizada no Congresso em outubro de 2019. Para mais detalhes, ver a matéria CNS critica redução de orçamento para remédios do SUS durante audiência no Senado: a EC no 95/2016, que congelou investimentos em saúde, foi duramente criticada durante o debate. Disponível em: <https://bit.ly/30D22MW>. Acesso em: 8 ago. 2020. 
de medicamentos à comissão ocorreram em número muito abaixo ao de pedidos aprovados de incorporaçáo, o que revela crescimento da oferta dessas tecnologias no SUS (Caetano et al., 2019). O comportamento cumulativo das tecnologias no setor saúde, com ampliação das alternativas terapêuticas, é algo conhecido e reportado em literatura especializada (Santos, 2010).

A questão é que a ampliação da incorporação de novos medicamentos só não afetará a oferta dos produtos disponíveis se houver grande redução dos preços e das quantidades desses últimos, a ponto de o aumento do gasto em novos medicamentos ser compensado com a redução das despesas em produtos existentes. Isso na prática pode não acontecer, considerando o elevado preço dos novos medicamentos (Bermudez et al., 2016). Logo, em contexto de restrição orçamentária, novas incorporaçóes podem resultar em grande redução da quantidade adquirida de outros medicamentos, comprometendo a disponibilidade desses produtos no SUS.

Na tabela 8, apresenta-se a decomposiçáo do gasto anual em medicamentos pelos dois indutores principais, preço e quantidade, dos medicamentos coincidentes entre dois períodos, ano de comparação e o imediatamente anterior. Observa-se significativa contribuição da redução dos preços em 2011, com impacto negativo sobre o gasto também nos anos seguintes, mas em menor magnitude. Além da contribuição das oscilaçôes da quantidade, levando a aumento ou à redução do gasto anual.

TABELA 8

Decomposição do gasto do MS em medicamentos coincidentes entre dois períodos da lista dos componentes da $\mathrm{AF}^{1}$ para as variáveis preço e quantidade (2010-2019)

\begin{tabular}{|c|c|c|c|c|c|c|}
\hline \multirow{2}{*}{ Ano } & \multirow{2}{*}{ Gasto anual } & \multicolumn{4}{|c|}{ Impacto no gasto dos itens coincidentes entre dois períodos ${ }^{2}$} & \multirow{2}{*}{$\begin{array}{l}\text { Gasto em outros } \\
\text { medicamentos }\end{array}$} \\
\hline & & Preço & Quantidade & Alteração & Valor total dos itens & \\
\hline 2010 & 3.574 .910 & - & - & - & - & - \\
\hline 2011 & 4.817 .134 & -1.030 .883 & 1.598 .640 & 567.757 & 3.979 .477 & 837.657 \\
\hline 2012 & 3.611 .436 & -543.740 & 155.933 & -387.806 & 2.965 .407 & 646.029 \\
\hline 2013 & 4.678 .757 & -701.843 & 1.071 .496 & 369.652 & 3.386 .083 & 1.292 .673 \\
\hline 2014 & 4.338 .574 & -211.695 & -207.398 & -419.093 & 3.124 .330 & 1.214 .244 \\
\hline 2015 & 5.147 .124 & -159.206 & -283.209 & -442.415 & 2.739 .583 & 2.407 .540 \\
\hline 2016 & 3.612 .425 & -868.605 & -513.233 & -1.381 .838 & 3.063 .813 & 548.612 \\
\hline 2017 & 3.454 .369 & -607.254 & 406.668 & -200.585 & 2.418 .940 & 1.035 .429 \\
\hline 2018 & 4.674 .269 & -210.491 & 532.513 & 322.022 & 3.037 .864 & 1.636 .405 \\
\hline 2019 & 3.522 .248 & -174.168 & -559.273 & -733.441 & 2.587 .590 & 934.658 \\
\hline \multicolumn{7}{|c|}{$\begin{array}{l}\text { Fonte: Siasg. } \\
\text { Elaboração da autora. } \\
\text { Notas: 'Medicamentos que possuem DDD estabelecida pela OMS. } \\
2 \text { Parte do efeito do resíduo sobre o gasto pode estar presente na lista compartilhada de medicamentos entre os anos, em razão de mudanças no padrão de } \\
\text { tratamento envolvendo os produtos disponiveis. } \\
{ }^{3} 0 \text { gasto em medicamentos não sobrepostos entre os dois anos analisados impacta o resíduo. }\end{array}$} \\
\hline
\end{tabular}


No tocante às limitações da análise apresentada neste texto, destacam-se duas relacionadas à metodologia. A primeira diz respeito à impossibilidade de se analisar a parcela do gasto em medicamentos para o subgrupo dos que náo possuem DDD estabelecida pela OMS. Uma alternativa seria a utilização de dados das prescrições de medicamentos ou da sua dispensação à população, mas não se dispõe dessas informaçôes no SUS. Talvez, nesses casos, se possa utilizar a quantidade física dos medicamentos mesmo com alguma perda de qualidade na informação gerada. Essa alternativa precisa ser investigada em estudo futuro.

A segunda limitação se refere à impossibilidade de decompor cada indutor principal em seus indutores secundários, utilizando-se da metodologia adotada neste texto. Os softwares de estatística disponibilizam funçôes que possibilitam o cálculo dos índices de preço e de quantidade, além da realização de outras análises envolvendo essas variáveis. O resíduo é calculado posteriormente usando a fórmula de decomposiçáo do índice do gasto. A estimativa do impacto dos indutores secundários depende, aparentemente, do desenvolvimento de programaçóes específicas para esses softwares. Algo que pode ser feito para a realização de outros estudos, com o apoio de pessoal especializado nesta temática.

Apesar dessas limitaçóes, destacam-se como vantagens da adoção da metodologia utilizada a facilidade de sua aplicação e a obtenção de estimativas robustas para os principais indutores do gasto em medicamentos, o que possibilita a produção de informação relevante sobre o assunto.

Uma terceira limitação da análise realizada neste texto envolve a informação do valor constante na base de dados utilizada para a apuração do gasto. Este é resultado da multiplicação do preço unitário do medicamento ${ }^{22}$ pela quantidade. No Siasg, o valor informado diz respeito ao montante negociado no processo de contratação, que corresponde, na execução orçamentária do MS, à despesa empenhada. Não se tem a informação dos valores efetivamente pagos às empresas para cada medicamento adquirido, com suas respectivas quantidades. Eventuais cancelamentos de compra e empenhos, parcial ou total, não são registrados nesse sistema de informação. Contudo, situaçôes como essas provavelmente ocorrem em baixa frequência e, com isso, seu impacto sobre os valores levantados não parece ser um grande problema.

22. Preço por unidade farmacotécnica (comprimido, cápsula, ampola etc.). 


\section{CONCLUSÕES}

Analisou-se neste texto a contribuição dos principais indutores do gasto direto do MS em medicamentos que integram a lista dos componentes da AF no período de 2010 a 2019. O gasto nesses produtos totalizou $\mathrm{R} \$ 41,4$ bilhóes nos dez anos considerados e apresentou comportamento errático, atingindo o maior valor em 2015 (R \$ 5,1 bilhóes). O gasto em 2019 ( $\mathrm{R}$ 3,5 bilhóes) foi ligeiramente menor do que o realizado em 2010 (R \$ 3,6 bilhôes). Em síntese, os resultados mostram grande variaçáo do gasto do MS em medicamentos da lista dos componentes da AF no período de 2010 a 2019, com maior ou menor contribuição de cada indutor principal na oscilação observada.

Tanto na análise base fixa (2010) quanto na análise período a período, os resultados mostram redução dos preços dos medicamentos e variação das quantidades para mais ou menos em uma lista compartilhada de medicamentos entre os anos comparados. O resíduo, que capta o gasto em outros medicamentos, assim como mudança no padráo de uso dos medicamentos da lista compartilhada, também variou segundo as duas metodologias.

O gasto em 2019, comparado ao realizado em 2010, teve reduçáo de 1,5\%, a qual foi induzida pela diminuição dos preços dos medicamentos comprados em ambos os anos (-55\%). Houve aumento da quantidade (77\%) e do resíduo (23,7\%). Na comparaçáo entre 2019 e 2018 , a queda do gasto foi de $24,7 \%$, induzida principalmente pela quantidade de medicamentos adquirida (-17\%). Também ocorreu redução dos preços $(-6 \%)$ e do resíduo $(-3,4 \%)$.

Além da redução da quantidade de medicamentos adquirida entre 2019 e 2018 (-17\%), houve queda da quantidade comprada entre 2016 e 2015 (-13\%), 2015 e 2014 (-9\%) e 2014 e 2013 (-6\%). Essa diminuição poderia estar relacionada à formação de estoques no ano anterior, mantendo-se a regularidade da oferta nas farmácias do SUS e o acesso da população aos medicamentos. Entretanto, há evidências para refutar essa hipótese. Reclamaçóes sobre a falta de medicamentos que estão sob a responsabilidade de aquisição do MS foram feitas nos últimos anos, especialmente em 2019. Assim, dificuldades administrativas e restrição orçamentária são as causas mais prováveis dessa redução.

Outra questão envolve o resíduo, que foi o principal indutor do gasto entre 2015 e 2014 (37,2\%) e entre 2018 e 2017 (21,2\%). Ele é impactado por alteraçóes no padrão de uso de medicamentos disponíveis entre dois períodos, assim como pela compra de outros medicamentos, em decorrência de incorporação, centralização ou aquisição de 
item não adquirido no ano anterior. Em contexto de restrição orçamentária como o atual, há grande dificuldade para garantir a oferta de tratamentos com os medicamentos incorporados ao SUS, considerando que fatores como o envelhecimento da populaçáo e o aumento da incidência/prevalência de determinadas doenças ampliarão a demanda por esses produtos. Nessa situaçáo, a incorporação de medicamentos é particularmente desafiadora, caso náo haja desincorporação de medicamentos e/ou o novo tratamento não seja capaz de reduzir o consumo de outros produtos.

Por fim, destaca-se a utilidade dos estudos sobre os indutores do gasto em medicamentos para a gestáo da assistência farmacêutica, na medida de sua contribuição para o entendimento do comportamento de variáveis que influenciam o gasto com esses produtos. Trata-se de importante aporte à tomada de decisão informada por evidências, que é reconhecidamente o caminho mais seguro em direção aos objetivos das políticas públicas.

\section{REFERÊNCIAS}

ADDIS, A.; MAGRINI, N. New approaches to analyzing prescription data and to transfer pharmacoepidemiological and evidence-based reports to prescribers. Pharmacoepidemiology and Drug Safety, Chichester, v. 11, n. 8, 721-726, 2002.

ALMEIDA, A. T. C.; VIEIRA, F. S. Copagamento dos usuários no Programa Farmácia Popular do Brasil: um estudo exploratório da rede conveniada. Rio de Janeiro: Ipea, 2020. (Texto para Discussão, n. 2585).

ALVES, J. C. et al. Immunosuppressants in Brazil: underlying drivers of spending trends, 20102015. Expert Review of Pharmacoeconomics \& Outcomes Research, London, v. 18, n. 5 , p. 565-572, 2018.

BCB - BANCO CENTRAL DO BRASIL. Índices de preços no Brasil. Brasília: Banco Central do Brasil, 2016. Disponível em: <https://bit.ly/2CP3wL4>. Acesso em: 22 jul. 2020.

BELLONI, A.; MORGAN, D.; PARIS, V. Pharmaceutical expenditure and policies: past trends and future challenges. Paris: OECD, 2016. (OECD Health Working Papers, n. 87).

BERMUDEZ, J. A. Z.; LUIZA, V. L.; SILVA, R. M. Assistência farmacêutica e acesso a medicamentos: superando a utopia. In: BERMUDEZ, J. A. Z.; COSTA, J. C. S.; NORONHA, J. C. (Orgs.). Desafios do acesso a medicamentos no Brasil. Rio de Janeiro: Ediçóes Livres, 2020.

BERMUDEZ, J. A. Z. et al. Novos medicamentos: quem poderá pagar? Cadernos de Saúde Pública, Rio de Janeiro, v. 32, supl. 2, 2016.

BOER, P.; RODRIGUES, J. F. D. Decomposition analysis: when to use which method? Economic Systems Research, v. 32, n. 1, p. 1-28, 2019. Disponível em: <https://bit.ly/30EBjyz>. Acesso em: 22 jul. 2020. 
BRASIL. Ministério da Saúde. Portaria no 3.916, de 30 de outubro de 1998. Aprova a Política Nacional de Medicamentos. Brasília: Ministério da Saúde, 1998. Disponível em: <https://bit.ly/31iTgUJ>. Acesso em: 22 jul. 2020.

Conselho Nacional de Saúde. Resolução no 338, de 6 de maio de 2004. Aprova a Política Nacional de Assistência Farmacêutica. Brasília: Conselho Nacional de Saúde, 2004. Disponível em: <https://bit.ly/2FM29hr>. Acesso em: 22 jul. 2020.

. Lei no 12.401 , de 28 de abril de 2011. Altera a Lei $\mathrm{n}^{\mathrm{o}}$ 8.080, de 19 de setembro de 1990, para dispor sobre a assistência terapêutica e a incorporação de tecnologia em saúde no âmbito do Sistema Único de Saúde - SUS. Diário Oficial da Uniáo, Brasília, 2011. Disponível em: <http://twixar.me/JzQn>. Acesso em: 22 jul. 2020.

Ministério da Saúde. Portaria GM/MS no 2.365, de 18 de outubro de 2012. Define a composição do kit de medicamentos e insumos estratégicos a ser encaminhado pelo Ministério da Saúde para a assistência farmacêutica às Unidades da Federação atingidas por desastres de origem natural associados a chuvas, ventos e granizo e define os respectivos fluxos de solicitação e envio. Diário Oficial da Uniáo, Brasília: 2012. Disponível em: <https://bit.ly/2XA0QYL >. Acesso em: 22 jul. 2020.

Ministério da Saúde. Componente Especializado da Assistência Farmacêutica: inovação para a garantia do acesso a medicamentos no SUS. Brasília: Ministério da Saúde, 2014. Disponível em: <https://bit.ly/31wLPZ0>. Acesso em: 22 jul. 2020.

Manual de consulta: itens de saúde Catmat/Siasg. Brasília: Ministério da Saúde, 2017. Disponível em: <https://bit.ly/30zgAgF>. Acesso em: 22 jul. 2020.

Contas do SUS na perspectiva da contabilidade internacional: Brasil, 2010-2014. Brasília: Ministério da Saúde, 2018. Disponível em: <https://bit.ly/3a9RBUr>.

CAETANO, R. et al. Incorporação de novos medicamentos pela Comissão Nacional de Incorporação de Tecnologias do SUS, 2012 a junho de 2016. Ciência \& Saúde Coletiva, Rio de Janeiro, v. 22, n. 8, p. 2513-2525, 2017.

CAETANO, R. et al. Desincorporação de tecnologias pela comissão nacional de incorporação de tecnologias, 2012 a junho/2016: um processo ainda incipiente no âmbito do SUS. In: CONGRESSO BRASILEIRO DE CIÊNCIAS SOCIAIS E HUMANAS EM SAÚDE, 8., 2019, João Pessoa. Anais... João Pessoa: ABRASCO, 2019. 2 p. Disponível em: <https://bit.ly/3gF5tIx>. Acesso em: 22 jul. 2020.

CANADA. Patented Medicine Prices Review Board (PMPRB). The drivers of prescription drug expenditures: a methodological report. Ottawa: PMPRB, 2013. Disponível em: $<$ https://bit.ly/3jxpLFN>. Acesso em: 22 jul. 2020.

CHAVES, G. C. et al. Medicamentos em situação de exclusividade financiados pelo Ministério da Saúde: análise da situação patentária e das compras públicas. Rio de Janeiro: Fiocruz, 2018. Disponível em: <https://bit.ly/3j6HDqc>. Acesso em: 22 jul. 2020.

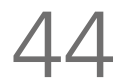


CNS - CONSELHO NACIONAL DE SAÚDE. Falta de medicamentos no SUS é tema discutido em reuniáo ordinária do CNS. Brasília: 26 abr. 2019. Disponível em: <https://bit.ly/3fBVAKv>. Acesso em: 22 jul. 2020.

ESPIN, J. et al. Projecting pharmaceutical expenditure in EU5 to 2021: adjusting for the impact of discounts and rebates. Applied Health Economics and Health Policy, Auckland, n. 16, p. $803-817,2018$.

GERDTHAM, U. G. et al. The effect of changes in treatment patterns on drug expenditure. Pharmacoeconomics, Auckland, v. 1, pt 2, p. 127-34, 1998.

GRUBBS, V. Medicare immunosuppressive drug coverage bills: we can afford them? American Journal of Transplantation, v. 19, n. 7, p. 1877-1878, 2019.

HSIEH, C. R.; SLOAN, F. A. Adoption of pharmaceutical innovation and the growth of drug expenditure in Taiwan: is it cost effective? Value in Health, Malden, v. 11, n. 2, p. 334-344, 2008.

IBGE - INSTITUTO BRASILEIRO DE GEOGRAFIA E ESTATÍSTICA. Conta-satélite de saúde Brasil: 2010-2017. Rio de Janeiro: IBGE, 2019. Disponível em: <https://bit.ly/3c2DWyi>. Acesso em: 22 jul. 2020.

IPEA - INSTITUTO DE PESQUISA ECONÔMICA APLICADA. Saúde. Políticas Sociais: acompanhamento e análise, Brasília, n. 26, p. 85-127, 2019.

JUNG, Y.; KWON, S. How does stronger protection of intellectual property rights affect national pharmaceutical expenditure? An analysis of OECD countries. International Journal of Health Services, Westport, v. 48, n. 4, p. 685-701, 2018.

KARAMPLI, E. et al. Pharmaceutical innovation: impact on expenditure and outcomes and subsequent challenges for pharmaceutical policy, with a special reference to Greece. Hippokratia, Thessaloniki, v. 18, n. 2, p. 100-106, 2014.

MORGAN, S. G. Quantifying components of drug expenditure inflation: the British Columbia Seniors' Drug Benefit Plan. HSR: Health Services Research, Chicago, v. 35, n. 5, p. 12431266, 2002.

. Drug spending in Canada: recent trends and causes. Medical Care, Philadelphia, v. 42, n. 7, p. 635-642, 2004.

Drug expenditure trends in the Canadian provinces: magnitude and causes from 1998 to 2004. Healthcare Policy, Toronto, v. 1, n. 1, p. 85-99, 2005.

MORGAN, S. G.; LEOPOLD, C.; WAGNER, A. K. Drivers of expenditure on primary care prescription drugs in high-income countries with universal health coverage. CMAJ, Ottawa, v. 189, n. 23, E794-E799, 2017.

MOUSNAD, M. A.; SHAFIE, A. A.; IBRAHIM, M. I. Systematic review of factors affecting pharmaceutical expenditures. Health Policy, Shannon, v. 116, p. 137-146, 2014. 
PETROU, P. The power of r-pharmaceutical sales decomposition in Cyprus public healthcare sector and determinants of drug expenditure evolution: any lessons learned? Expert Review of Pharmacoeconomics \& Outcomes Research, London, v. 14, n. 2, p. 289-300, 2014.

SANTOS, V. C. C. As análises econômicas na incorporação de tecnologias em saúde: reflexóes sobre a experiência brasileira. Dissertação (Mestrado) - Escola Nacional de Saúde Pública Sergio Arouca. Rio de Janeiro: Fiocruz, 2010. Disponível em: <https://bit.ly/2XFhlmE $>$. Acesso em: 22 jul. 2020.

SANTOS, I. S.; VIEIRA, F. S. Direito à saúde e austeridade fiscal: o caso brasileiro em perspectiva internacional. Ciências \& Saúde Coletiva, Rio de Janeiro, v. 23, n. 7, p. 2303-2314, 2018.

SHI, L.; YANG, H. Y.; CHENG, G. Time trends and determinants of pharmaceutical expenditure in China (1990-2009). Pharmacoeconomics, Auckland, v. 32, n. 3, p. 257-264, 2014.

SOPPI, A. et al. Growth of diabetes drug expenditure decomposed: a nationwide analysis. Health Policy, Shannon, v. 122, n. 12, p. 1326-1332, 2018.

THAI, L. P. et al. Cost driver analysis of statin expenditure on Australia's Pharmaceutical Benefits Scheme. Expert Review of Pharmacoeconomics \& Outcomes Research, London, v. 16, n. 3, p. 419-33, 2016.

VIEIRA, F. S. Evolução do gasto com medicamentos do Sistema Único de Saúde no período de 2010 a 2016. Rio de Janeiro: Ipea, 2018. (Texto para Discussão, n. 2356).

Desafios do Estado quanto à incorporaçáo de medicamentos no Sistema Único de Saúde. Brasília: Ipea, 2019. (Texto para Discussão, n. 2500).

WHITE, G. IndexNumR: a package for index number calculation. The Comprehensive R Archive Network, 2020a. Disponível em: <https://bit.ly/3jBQ3qL>. Acesso em: 22 jul. 2020. . Package 'IndexNumR'. The Comprehensive R Archive Network, 2020b. Disponível em: <https://bit.ly/2XH5CUA>. Acesso em: 22 jul. 2020.

WHO - WORLD HEALTH ORGANIZATION. DDD: Definition and general considerations. Genebra, Suíça: WHO, 2018. Disponível em: <https://bit.ly/2Eg8fpr>. Acesso em: 22 jul. 2020. 

Ipea - Instituto de Pesquisa Econômica Aplicada

\title{
EDITORIAL
}

\section{Chefe do Editorial}

Reginaldo da Silva Domingos

\section{Assistentes da Chefia}

Rafael Augusto Ferreira Cardoso

Samuel Elias de Souza

\section{Supervisão}

Camilla de Miranda Mariath Gomes

Everson da Silva Moura

\section{Revisão}

Amanda Ramos Marques

Ana Clara Escórcio Xavier

Clícia Silveira Rodrigues

Idalina Barbara de Castro

Luiz Gustavo Campos de Araújo Souza

Olavo Mesquita de Carvalho

Regina Marta de Aguiar

Hellen Pereira de Oliveira Fonseca (estagiária)

Ingrid Verena Sampaio Cerqueira Sodré (estagiária)

\section{Editoração}

Aeromilson Trajano de Mesquita

Anderson Silva Reis

Cristiano Ferreira de Araújo

Danilo Leite de Macedo Tavares

Jeovah Herculano Szervinsk Junior

Leonardo Hideki Higa

\section{Capa}

Danielle de Oliveira Ayres

Flaviane Dias de Sant'ana

\section{Projeto Gráfico}

Renato Rodrigues Bueno

The manuscripts in languages other than Portuguese published herein have not been proofread.

\author{
Livraria Ipea \\ SBS - Quadra 1 - Bloco J - Ed. BNDES, Térreo \\ 70076-900 - Brasília - DF \\ Tel.: (61) 2026-5336 \\ Correio eletrônico: livraria@ipea.gov.br
}



Composto em adobe garamond pro 12/16 (texto) Frutiger 67 bold condensed (títulos, gráficos e tabelas) Brasília-DF 



\section{Missão do Ipea}

Aprimorar as políticas públicas essenciais ao desenvolvimento brasileiro por meio da produção e disseminação de conhecimentos e da assessoria ao Estado nas suas decisões estratégicas.

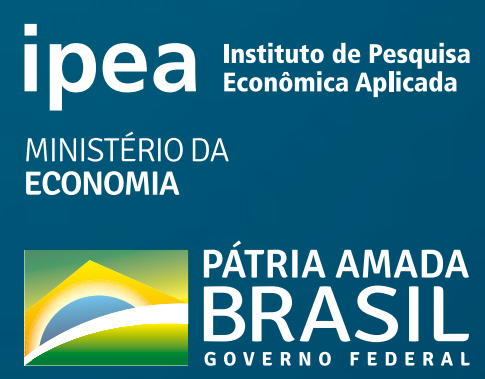

